\title{
Numerical and Experimental Investigation of Aerodynamic Performance of Vertical-Axis Wind Turbine Models with Various Blade Designs
}

\author{
Mosfequr Rahman', Travis E. Salyers' ${ }^{1}$, Adel El-Shahat ${ }^{2}$, Marcel Ilie ${ }^{1}$, \\ Mahbub Ahmed ${ }^{3}$, Valentin Soloiu ${ }^{1}$ \\ ${ }^{1}$ Mechanical Engineering Department, Georgia Southern University, Statesboro, USA \\ ${ }^{2}$ Electrical Engineering Department, Georgia Southern University, Statesboro, USA \\ ${ }^{3}$ Engineering \& Physics Department, Southern Arkansas University, Magnolia, USA \\ Email: mrahman@georgiasouthern.edu, ts03026@georgiasouthern.edu, aahmed@georgiasouthern.edu, \\ milie@georgiasouthern.edu, mkahmed@saumag.edu,vsoloiu@georgiasouthern.edu
}

How to cite this paper: Rahman, M., Salyers, T.E., El-Shahat, A., Ilie, M., Ahmed, M. and Soloiu, V. (2018) Numerical and Experimental Investigation of Aerodynamic Performance of Vertical-Axis Wind Turbine Models with Various Blade Designs. Journal of Power and Energy Engineering, 6, 26-63.

https://doi.org/10.4236/jpee.2018.65003

Received: May 10, 2018

Accepted: May 28, 2018

Published: May 31, 2018

Copyright ( $\odot 2018$ by authors and Scientific Research Publishing Inc. This work is licensed under the Creative Commons Attribution International License (CC BY 4.0).

http://creativecommons.org/licenses/by/4.0/

\begin{abstract}
Due to the importance and advantages of Vertical-axis wind turbines (VAWTs) over traditional horizontal-axis wind turbines (HAWTs), this paper is implemented. Savonius turbines with drag-based rotors are adopted from the two more extensive arrangements of vertical wind turbines because of their advantages. In this paper, six diverse rotor plans with measure up to cleared regions are analyzed with exploratory wind burrow testing and numerical reenactments. These proposed models incorporate a conventional Savonius with two different edges criteria and 90 degree helical bend models with two, three and four sharp edges. The models were designed using SolidWorks software then the physical models were 3D printed for testing. A subsonic open-sort wind burrow was utilized for Revolution per Minute (RPM) and torque estimation over a scope of wind speeds. ANSYS Fluent reenactments were utilized for dissecting streamlined execution by using moving reference outline and sliding lattice display methods. A 3-dimensional and transient strategy was utilized for precisely tackling torque and power coefficients. The five new rotor geometries have important advantages such as making a focal point of weight advance from the hub of revolution and causing more noteworthy torque on the turbine shaft contrasted with the customary Savonius turbine. Our new models with the names of CC model and QM model display cross-areas lessen the aggregate scope of negative torque on the edges by 20 degrees, contrasted with the customary Savonius demonstrate. Helical
\end{abstract}


plans are better spread the connected torque over a total transformation resulting in positive torque over every single operational point. Moreover, helical models with 2 and 3 cutting edges have the best self-starting ability in low wind speeds. Helical VAWT with 3 edges starts revolution of 35 RPM at only $1.4 \mathrm{~m} / \mathrm{s}$ wind speed under no generator stacking. The most noteworthy power coefficient is accomplished, both tentatively and numerically, by the helical VAWT with 2 sharp edges.

\section{Keywords}

Vertical-Axis Wind Turbine, VAWT, Savonius, Helical, Wind Tunnel, Computational Fluid Dynamics (CFD), ANSYS Fluent

\section{Introduction}

Wind energy is one of the most viable renewable sources today due to its year-round availability, and pollution-free nature. According to the Wind Vision Report, published by the U.S. Department of Energy, wind energy is the largest source of added renewable energy generation in the United States since 2000. Experts predict that, with proper development, $20 \%$ of the nation's electricity can be supplied by wind by the year 2030 , and $35 \%$ by 2050 . The report states that a key to achieving this goal is to improve the potential of low-wind-speed locales [1]. Because of this, many works are underway involving the efficiency of wind energy conversion systems, especially for regions with low average wind velocities.

Horizontal-axis wind turbines (HAWTs) have been in practice for some time and are heavily favored over Vertical-axis wind turbines (VAWTs) for large-scale power generation; however, research of VAWTs has gained growing interest in recent years because of the opportunities available for small-scale and off-grid power generation which favors the use of VAWTs. VAWTs have many advantages for small scale wind energy applications. Interest in VAWT technology has recently grown due to potential for off-grid power supply in several different applications. One of the greatest advantages for VAWTs over traditional HAWTs is the ability to self-start in some designs. Under low wind speed conditions, many VAWTs begin to rotate without the added expense of actuators or controls. For VAWTs the generator may be located on the ground rather than high in the air. This provides much more convenient and cost efficient installation and maintenance than that of HAWTs. Another advantageous feature of VAWTs is the fact that they can accept wind from all directions. Regardless of where the wind is coming from, the turbines generally perform equally as well. For this reason, VAWTs are preferred over HAWTs where unsteady and low speed wind conditions exist.

There are three important non-dimensional coefficients that characterize turbine performance. Tip-speed ratio $(T S R)$ is the ratio of blade tip speed to the 
free-stream wind velocity. It is the product of angular velocity and overall radius, divided by the wind velocity. The moment coefficient $(\mathrm{Cm})$, also known as the torque coefficient, characterizes the amount of torque generated by the blade geometry. It is the measured torque divided by the theoretical torque value available in the wind. Power coefficient is the product of tip-speed ratio and moment coefficient. The power coefficient is the efficiency of the turbine useful way for comparing the efficiencies of different wind turbine designs is plotting the power coefficient vs. tip-speed ratio. Savonius VAWTs operate in a tip-speed ratio range of 0 to 1.2 and have a maximum efficiency of 20\%. Darrieus rotors operate in higher wind speeds and achieve a maximum efficiency of 35 percent, while HAWTs enjoy the highest power coefficients of any turbine type.

Savonius wind turbines are drag-type VAWTs with negligible lift forces. The traditional Savonius rotor is made up of two opposite-facing semicircular buckets. Rotation is caused due to a difference in pressure between the advancing and retreating blades. When wind strikes the blades of the turbine, two components of drag force are generated on each blade surface. Normal drag force $\left(F_{n}\right)$ acts perpendicular to the blade wall and tangential drag force $\left(\mathrm{F}_{t}\right)$ acts along the tangential direction of each blade [2]. Drag-based Savonius VAWTs exemplify high starting torque and perform best at low tip-speed ratios. Much research has been conducted regarding two and three blade rotors of this type. Morshed, Rahman, and Ahmed [3] provided analysis of three-bladed Savonius rotors with different overlap ratios. Models with overlap ratio of 0.12 and 0.26 were compared to a model with no overlap. A numerical investigation using GAMBIT and FLUENT was conducted along with wind tunnel experimentation. It was concluded in the study that for all tested wind speeds, the model with 0.12 overlap attained the highest experimental torque coefficient. At higher wind speeds the same model demonstrated the best experimental power coefficient; however, the model with no overlap had the better power coefficient at low wind speed.

Rather than conventional Savonius types, some have investigated alternative drag-based designs. Ghatage et al. [4] researched the effects of twisted rotors. It was found that twisting the blades provided enhanced efficiency of the turbine. The experimental results agreed with CFD simulations. It was also concluded that a twisted two-blade arrangement outperformed a twisted design with three blades. The optimum twist angle for this study was found to be $30^{\circ}$. The use of stacked Savonius rotors also show increases in wind conversion efficiency compared to a single rotor [5]. This is one promising example of a multistage turbine. It was found that the Savonius rotor produced a negative torque coefficient within two narrow ranges of rotation, reflecting an intermittent disturbance to the flow field. In contrast, the torque coefficient for the spiral design remained positive during the entire rotational cycle. The maximum torque coefficient $(C q)$ for the twisted blade was 0.43 while the maximum $C q$ recorded with the traditional bade was less than 0.30 with more severe fluctuation [6]. In addition to a standard S-blade (Savonius) and helical rotor, [7] added a three-bladed Savonius 
model and a two-stage model to their study. The helical rotor showed a $20 \% \mathrm{im}$ provement in efficiency over the other models, and the three-bladed Savonius model attributed the lowest recorded power coefficient in the study. In another study, numerical analysis was performed on a Savonius rotor with 45 degree twist angle. It was found that significant power coefficient increase occurred at rotor angle of 90 degrees in respect to incoming air velocity [8]. Kamoji et al. [9] proposed a helical Savonius rotor with a 90 degree twist angle. It was found that torque coefficient remained positive for all operating angles, and the maximum power coefficient was obtained by the helical model with no overlap, no shaft, and aspect ratio of 0.88 . Ricci et al. [10], developed different configurations of Savoinus rotors for the purpose of street lighting applications. The experiment was conducted in a closed loop wind tunnel. Three models were tested: straight blade, 90 degree twist, and 105 degree twist. The best results were obtained with the 105 degree twist helical rotor with end plates and central gap. The maximum $C p$ of 0.251 occurred at tip-speed ratio of 0.899 . The effects of various end plates were presented by Jeon et al. [11]. The researchers added four different end plates of various shape and size to helical models. The twist angle for these models 180 degrees. The use of end plates on top and bottom increased the power coefficient by up to $36 \%$, compared to a model with no end plates. It was determined that circular plates with area the same as that of the swept area of the turbine maximized power. Overlapping the blades allows for airflow to occur between them, and the overlap condition is defined by the gap between blade and shaft, relative to the turbine radius. Deb et al. [12] experimented with a 20 degree twist helical Savonius rotor at different overlap conditions. Six different overlap ratios ranging from $0 \%$ to $20 \%$ were investigated. It was concluded that rotor performance increases with increasing overlap ratio up to a certain limit. The maximum power coefficient obtained was 0.289 with an overlap ratio of $12.76 \%$. The recommended tip-speed ratio for best performance of this design was 0.51 - 0.90. A study performed by Wenehenubun et al. [13] addressed the influence of increasing number of blades on turbine rotation. Two, three, and four straight-blade Savonius models were analyzed with wind tunnel testing and numerical simulation using ANSYS software. It was found that the four blade turbine performed best at lower tip-speed ratios. At higher tip-speed ratios, the model with three blades produced the highest power coefficient. Saha et al. [14] found that for multistage systems, maximum power coefficient is produced with two twisted blades and two stages.

Lift-based VAWTs is a popular research area because of the higher power coefficient potential. Typically Darrieus rotors consist of straight, vertical airfoils. The most prevalent work in this area is the optimization of airfoil shape. This is done by testing different designs by the use of two-dimensional Computational Fluid Dynamics. Aerodynamic investigations are performed numerically in order to improve maximum output torque and power coefficients [15]. Designs for lift-based VAWTs are not limited to only vertical blades. Armstrong et 
al. [16] analyzed the effects of canted blades and canted blades with fences in comparison to straight blades. The straight-blade and canted-blade H-Darrieus turbines were tested at very high Reynolds numbers. The experiment indicated that rotors with canted blades experienced much less flow reversal than that of the vertical blades. The addition of fences on the canted blades increased power and decreased the tip-speed ratio at which maximum power occurred. Many techniques have been researched to improve the start-up of lift-based Darrieus rotors. Beri, Habtamu, and Yingxue, [17], performed simulations of modified airfoils with a hinged tail using FLUENT. A conventional NACA0018 airfoil model was allowed to flex $15^{\circ}$ at the trailing edge. The hinge was located back $70 \%$ of the blade length. Moving mesh technique was utilized to investigate two-dimensional flow around the model. Unsteady flow simulations were performed at low tip-speed ratios ranging from 0.1 to 1.0 and compared to simulations of a known self-starting airfoil model. The simulation results indicated that the hinged model had better self-starting performance for all flow conditions. Another effort to enhance performance of VAWTs involves stacking multiple rotors on one axis. Multistage turbines consist of at least two tiers containing separate blade configurations. Gorelev and Krivopitsky, [18], designed two-tier wind turbines made up of straight-bladed Darrieus rotors. The full-scale models achieved self-start rotation without any added devices. Two separate configurations were fabricated with levels of staggered airfoils. The first used six blades in total of three on top and three on bottom. The second model was built with two blades on the top tier and two on the bottom. Of all the experimental tests, a maximum efficiency of $40 \%$ was reached for a $3-\mathrm{kW}$ apparatus.

Work by Kou et al. [19] involved a multitier Savonius rotor combined with a three-bladed Darrieus gyromill rotor. The addition of the Savonius rotor enhanced conversion efficiency compared to only gyromill. Also, the required wind speed for self-starting was successfully lowered for the hybrid design. Gupta, Biswas, and Sharma [20] combined a Savonius with an egg-beater type Darrieus rotor. Their design consisted of three-bladed Darrieus and three-bladed Savonius. Varying overlap ratios were implemented in the Savonius rotor. The model was tested in a subsonic wind tunnel and compared to a simple Savonius rotor. For the hybrid turbine configuration, it was found that maximum performance occurred with no overlap geometry in the Savonius rotor. It was concluded in the study that the power coefficient was significantly greater for the hybrid model than for that of the Savonius rotor at all overlap conditions.

Cambered S818 airfoil blades display better self-starting characteristics at most azimuthal angles, and Savonius rotors provide the best start-up performance. In order to achieve completely self-starting rotor at all azimuthal positions, a hybrid system was modeled by Bhuyan and Biswas [21]. The H-Savonius rotor contained a three-bladed cambered Darrieus rotor with a Savonius rotor as its starter. Self-starting capability was determined by positive static torque coefficient values at all angles. Five different overlap conditions were tested for the 
Savonius part of the rotor. Efficiency of the hybrid model was compared with a simple H-rotor. The optimum overlap ratio was found to be 0.15 at a tip speed ratio of 2.29 and Reynolds number of $1.29 \times 10^{5}$. The optimized hybrid model achieved a maximum power coefficient of 0.34 which resulted in a significant increase in power performance from the H-rotor only model. The hybrid $\mathrm{H}$-Savonius model in this study provided better power performance than most existing VAWT rotors while possessing the ability to self-start. According to Islam et al. [22], the best numerical models validated for VAWT computations fell into three categories. The three categories were momentum model, vortex model, and cascade model. Each of these had specific advantages and disadvantages, but it was concluded that the cascade model gave smooth convergence at higher tip-speed ratios with reasonable accuracy. For drag-type rotors, Pope et al. [23] presented a new correlation for performance analysis. The correlation predicted power coefficient in terms of dimensionless numbers and specific turbine geometries. The robust correlation was extended to various rotor geometries. This CFD technique proved to be a useful design tool for improving Savonius VAWTs.

Recently, Alaimo et al. [24] completed an analysis of VAWTs with computational fluid dynamics (CFD) using ANSYS Fluent software. The goal of the study was to compare performance of straight and helical shape turbines. The authors used two-dimensional and three-dimensional approaches to solve the Reynolds Averaged Navier-Stokes (RANS) equations. Two-dimensional simulations were used to approximate performance parameters such as torque, power, lift, and drag coefficients. Three-dimensional simulations were then carried out for a more accurate determination of aerodynamic properties of the complex geometries associated with helical blades. Static and dynamic numerical results were presented. The realizable k-epsilon turbulence model is the recommended two equation turbulence model to account for rotation and strain in the flow [25]. For dynamic simulations, a moving reference frame solution should serve as the initial condition for the sliding mesh calculation [26]. HAWT Advantages [27] are: It has high efficiency; It permits stronger wind in sites with wind shear; In some, every ten meters up the wind speed can increase by $20 \%$ and the power output by $34 \%$; It involves different types of reciprocating actions and It requires airfoil surfaces to backtrack against the wind for part of the cycle. HAWT Disadvantages [27] [28] are: It requires massive tower construction; It disrupts the appearance of the landscape; Sometimes it creates local opposition; It suffers from fatigue and structural failure caused by turbulence and It requires an additional yaw control mechanism to turn the blades toward the wind. However, Vertical Axis Wind Turbine (VAWT) advantages [28] [29] are the main advantage of having main rotor shaft arranged vertically is that the wind turbine does not need to be pointed into the wind; It is better choice for sites with highly variable wind direction or turbulent winds; With a vertical axis, the tower does not need to support it because most of the components are placed on to the ground; They can produce electricity in any wind direction; Low production cost as 
compared to horizontal axis wind turbines; Easy installation in comparable with other wind turbine types; Easy for transportation; Cheap maintenance costs; It can be installed in urban areas and Low risk for human and birds; It is suitable for various areas such as the mountains. VAWT Disadvantages [29] are It has lower efficiency in comparable with HAWT; It needs an initial push to start; It has additional drag created when their blades rotate; It has a relative high vibration and It can create noise pollution.

\subsection{Motivation and Goals of Research}

Based on the literature review, some gaps in the VAWT research are identified. First, only semi-circle geometries are used for Savonius blades. Second, there is no available data for helical models with 90 degree twist angle, even though positive results are seen with higher twist angles in low TSR ranges. Also, there is plenty of research involving changing the number of blades for standard Savonius turbines but none for varying blade number of helical models. Lastly, very few researchers have developed three-dimensional and transient flow simulations for the study of aerodynamic behavior of vertical-axis wind turbines. With these opportunities for advancing the body of knowledge in mind, the following goals are outlined for this study:

- Model 3 Savonius blade geometries in SolidWorks with different cross-section geometries

- Validate increased performance of new designs with numerical simulations

- Complete CAD models of helical designs with 2-4 blades

- 3D print 6 models for experimental testing

- Experimentally determine the self-starting capabilities and power coefficients of the 6 VAWT models (wind velocity, RPM, torque)

- Investigate performance of helical models with ANSYS Fluent simulation and plot power coefficient vs. tip-speed ratio

\subsection{Scope of Research}

In the present study, six different rotor designs are analyzed. Wind tunnel experiments are conducted to find reactional torque and rotations per minute (RPM) from which turbine efficiencies are calculated. Computational Fluid Dynamic (CFD) simulations are performed with ANSYS Fluent to study aerodynamic characteristics of the models. The objectives of the research are as follows:

- Increase power coefficient of Savonius turbines by creating new blade geometries

- Determine the self-starting capabilities of the new models

- Develop a three-dimensional and transient model for VAWT simulation

It is hypothesized that the new "CC" and "QM" models will achieve higher maximum torque and power coefficients than the conventional Savonius model. Also, the helical models will create positive torque on the turbine shaft over all operational angles of rotation and possess the ability to self-start in lower wind 
speeds, increasing overall performance.

\section{Methodology}

This section covers procedures for the experimental and numerical studies. An open-type, subsonic wind tunnel is used for the experimental portion of this study. At each wind speed tested, reactional torque, wind velocity, and RPM data are collected. Reactional (static) torque is measured for every 10 degrees of turbine rotation. ANSYS Fluent software is used for computational fluid dynamics simulations. The simulations are performed in three dimensions to gather moment coefficient data over time for one rotation.

\section{Model Design and Fabrication}

In total, six different VAWT models are tested in the study. Each model is developed using Solid Works commercial CAD software. Due to some complex and twisted geometries, the models are 3D printed using fused deposition modeling (FDM) and stereo lithography (SLA) methods. The models are named SAV, CC, QM, Helical 2, Helical 3, and Helical 4 for reference. The traditional Savonius model with straight blades, SAV, is used for benchmarking and comparing results of the new designs. The SAV cross-section can be seen in Figure 1.

Each model in the study is designed with a 4.2 inch blade diameter $(D)$ and blade height $(H)$ of 4 inches; therefore, the swept area $(A)$ is kept consistent across all models. Cross-sectional views of the new Savonius designs, "CC" model and "QM" model, are displayed in Figure 2.

CC is modeled with slightly smaller diameter buckets of 1.5 inches, connected

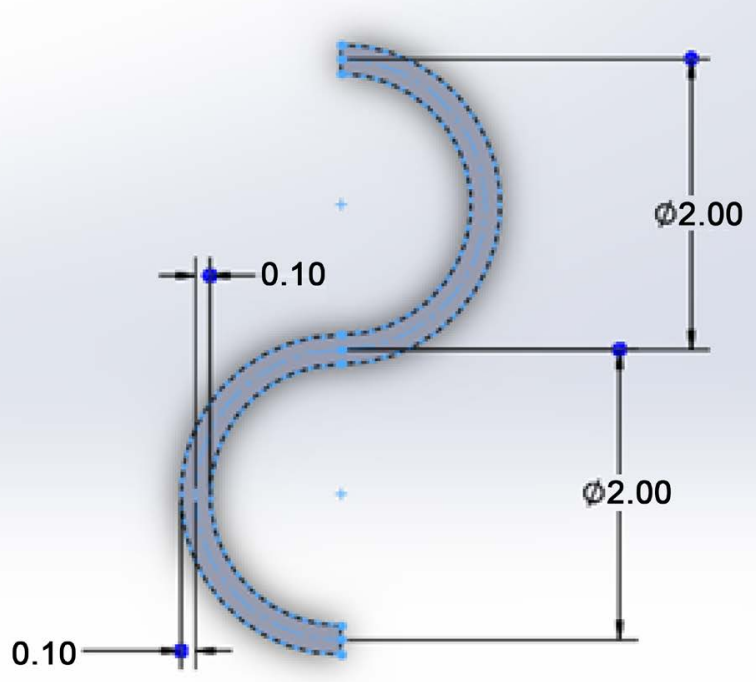

Figure 1. SAV model cross-sectional view with dimensions. 

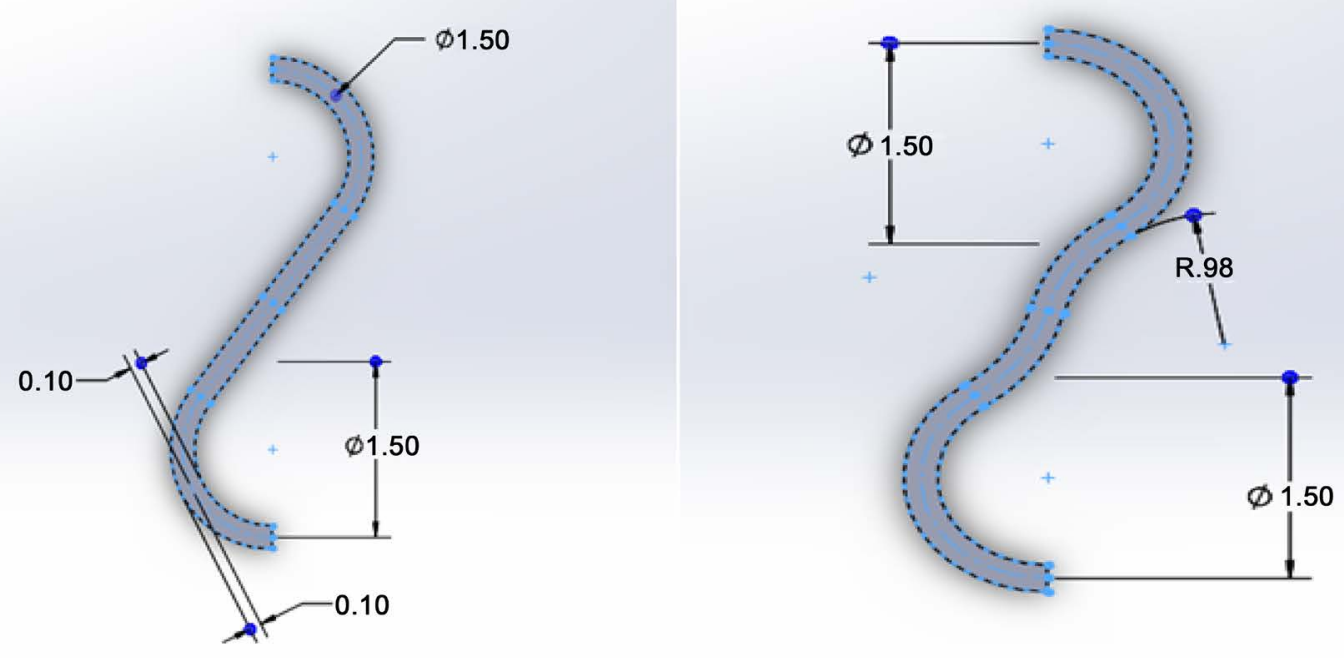

Figure 2. CC model (left) and QM model (right) cross-sectional views with dimensions.

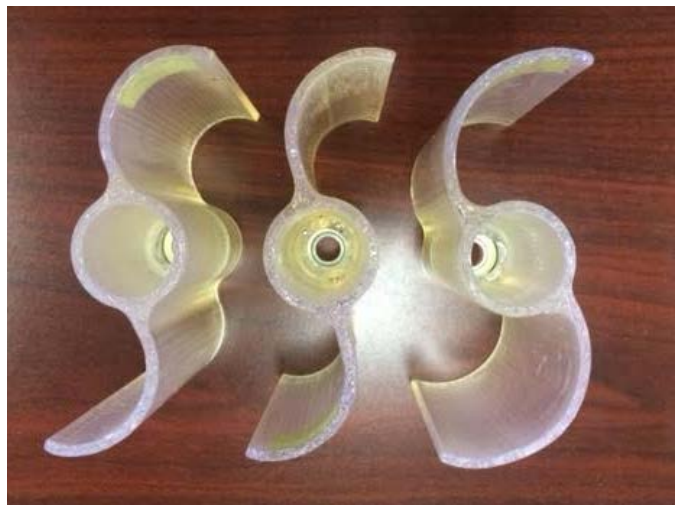

Figure 3. SLA 3D printed models.

with a tangent line. The QM model has the same dimensions with a curved line connecting the 2 blades. The SLA 3D printed models are presented in Figure 3.

The other three VAWT models in the study are constructed with a helical twist of 90 degrees. Helical 2, Helical 3, and Helical 4 have similar cross-sections to that of the traditional Savonius with varying number of blades from 2 to 4 . Details of the blade-tip helix for each of these models may be seen in Figure 4.

Completed CAD models of the VAWTs with 90 degree helical twist may be seen in Figure 5. Pictured from left to right, these models are Helical 2, Helical 3 , and Helical 4 . The helical models spread torque values more evenly over a full rotation, resulting in positive torque coefficients for all operating angles.

These physical models are then created from PLA plastic with a FDM 3D printer for experimental testing, shown in Figure 6.

\section{Experiment Set-Up and Equipment}

The Georgia Southern wind energy laboratory is equipped with a subsonic open-type wind tunnel for experimental testing. The existing wind tunnel and 

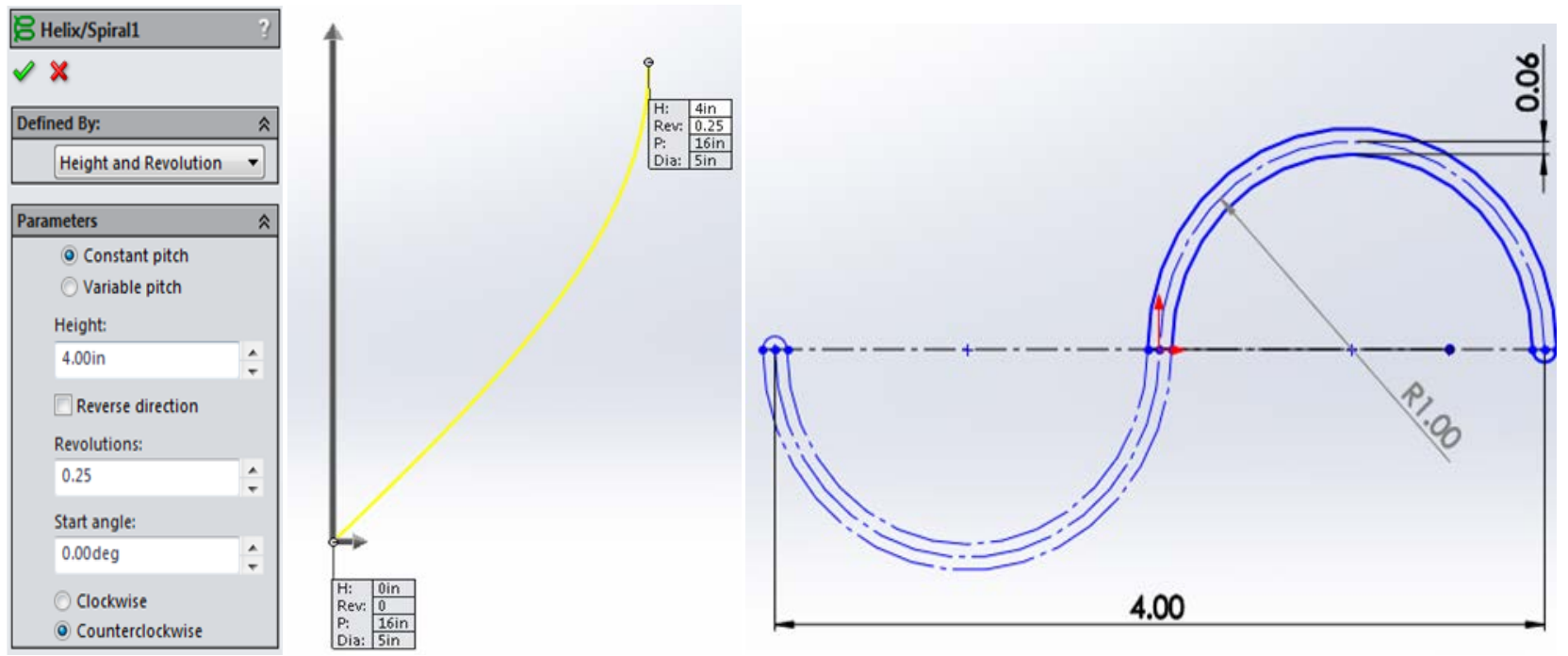

Figure 4. Details of 90 degree twist used for helical models.
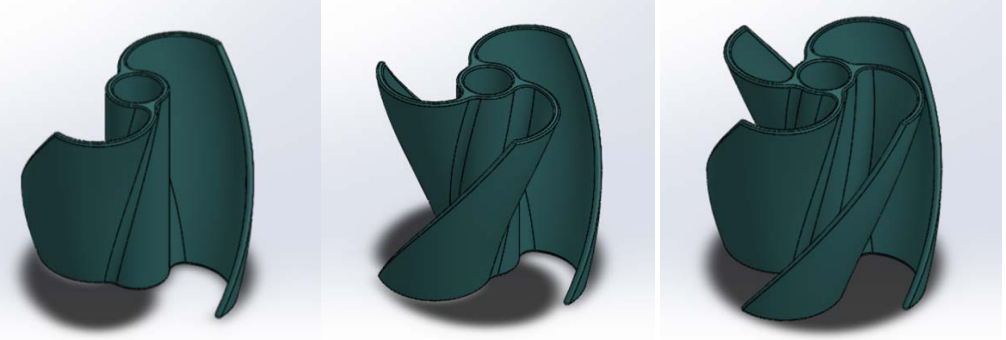

Figure 5. CAD models of Helical 2, Helical 3, and Helical 4 (from left to right).

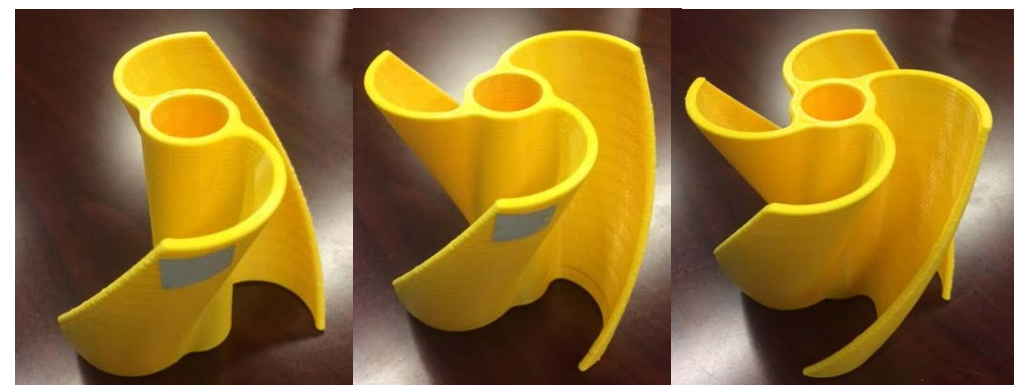

Figure 6. FDM 3D printed helical models.

test section are shown in Figure 7 and the sections are shown in Figure 8. The wind tunnel inlet is shown in the far left of the photo, followed by a honeycomb section for laminar flow. The fan is controlled by a Huanyang variable frequency drive. Another honeycomb section immediately follows the fan. Next is a diverging-converging section with a 9 to 1 area ratio to the $2 \mathrm{ft}$. by $2 \mathrm{ft}$. wind tunnel outlet. The VAWT test section frame is also showed at the wind tunnel outlet.

\subsection{Wind Speed}

Free stream velocity through the test section is easily controlled with the variable 


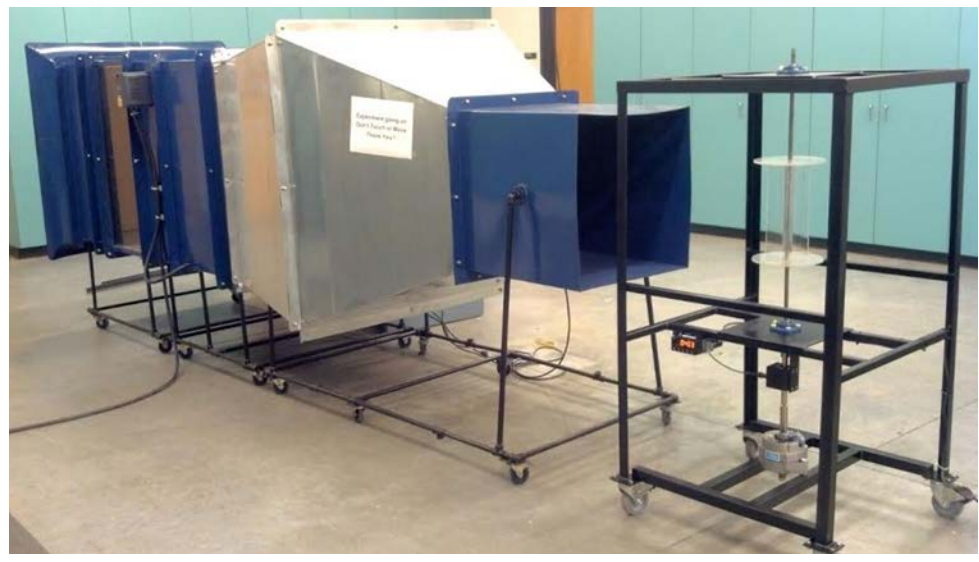

Figure 7. Sub-sonic Wind tunnel configuration.

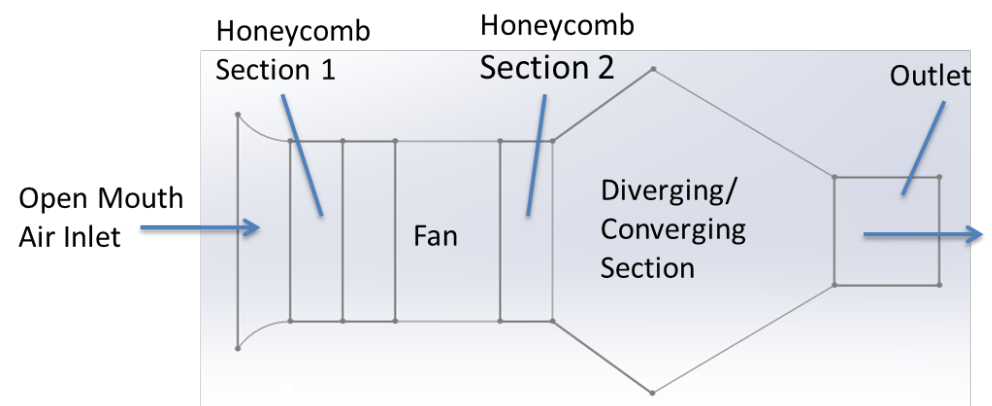

Figure 8. Wind tunnel sections schematic.

frequency drive (VFD) operator interface. Consistent and maintainable RPMs of the motor depend on the frequency, measured and displayed in Hertz, transmitted from the VFD. The internal fan produces wind speeds of 0 to $13 \mathrm{~m} / \mathrm{s}$ through the outlet.

A hand held anemometer is used to measure wind velocity for each test. Wind speed is measured about 6 inches in front of the model and centered on the axis of rotation. The instrument is capable of measuring current, maximum, or average wind speed. Each time the VFD is used to alter wind conditions, current wind speed is measured in time intervals of $2-10$ seconds. For each experiment at a given wind speed, 5 separate readings of current wind velocity are taken to ensure consistent wind conditions. The anemometer has a range of 0.2 to $30 \mathrm{~m} / \mathrm{s}$ and is accurate to $0.1 \mathrm{~m} / \mathrm{s}$.

\subsection{RPM measurement}

A small circular base with 2.5 in. vertical shaft is used for RPM measurement. Two sealed stainless steel ball bearings are fitted inside the models to allow for free rotation on the fixed shaft. A laser tachometer is used to measure RPM of the models under varying wind conditions, seen in Figure 9 with \pm 0.05 percent accuracy. A small piece of reflective tape is applied to the top of one blade to reflect the infrared light. A detector on the tachometer receives the reflected light and detects changes in frequency. The frequency change over time gives the ro- 
tational speed of the VAWT models. All meters are calibrated for zero errors.

\subsection{Torque Measurement}

A reactional torque meter with error of no more than $\pm 0.1 \%$ of $1000 \mathrm{Nm}$, or \pm 1 $\mathrm{Nm}$ is used for each model under increasing wind speeds. For each wind condition, torque is measured at every 10 degrees of turbine rotation. The torque meter and experimental setup is displayed in Figure 10.

The base plate of the torque measurement fixture is marked for every $10 \mathrm{de}$ grees of rotation. It is important to define the turbine angle relative to incoming wind velocity. The CC and Helical 2 models are positioned on the fixture at an angle of zero degrees relative to incoming wind in Figure 11. A 10 degree clockwise rotation is equal to a position angle of 10 degrees. This definition of turbine angle relative to incoming wind is consistent throughout the research. Fluid characteristic parameters are well depicted from ANSYS software.

\subsection{Analysis}

Once torque data is calculated, analysis must be done to compare the performance of the models to other research. Non-dimensional coefficients are used for comparison to other similar research and validation of the experiment. Three

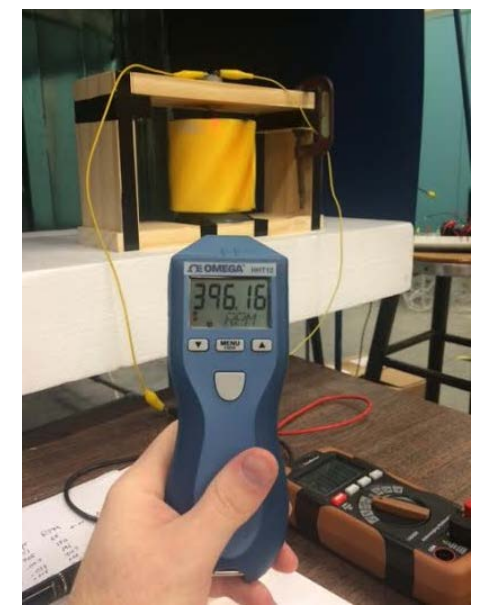

Figure 9. Laser tachometer for RPM measurement.

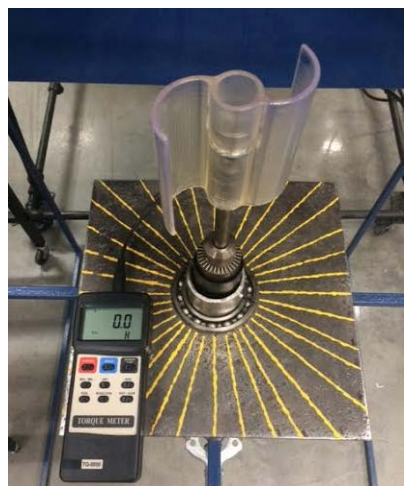

Figure 10. The reactional (static) torque meter and experimental setup. 

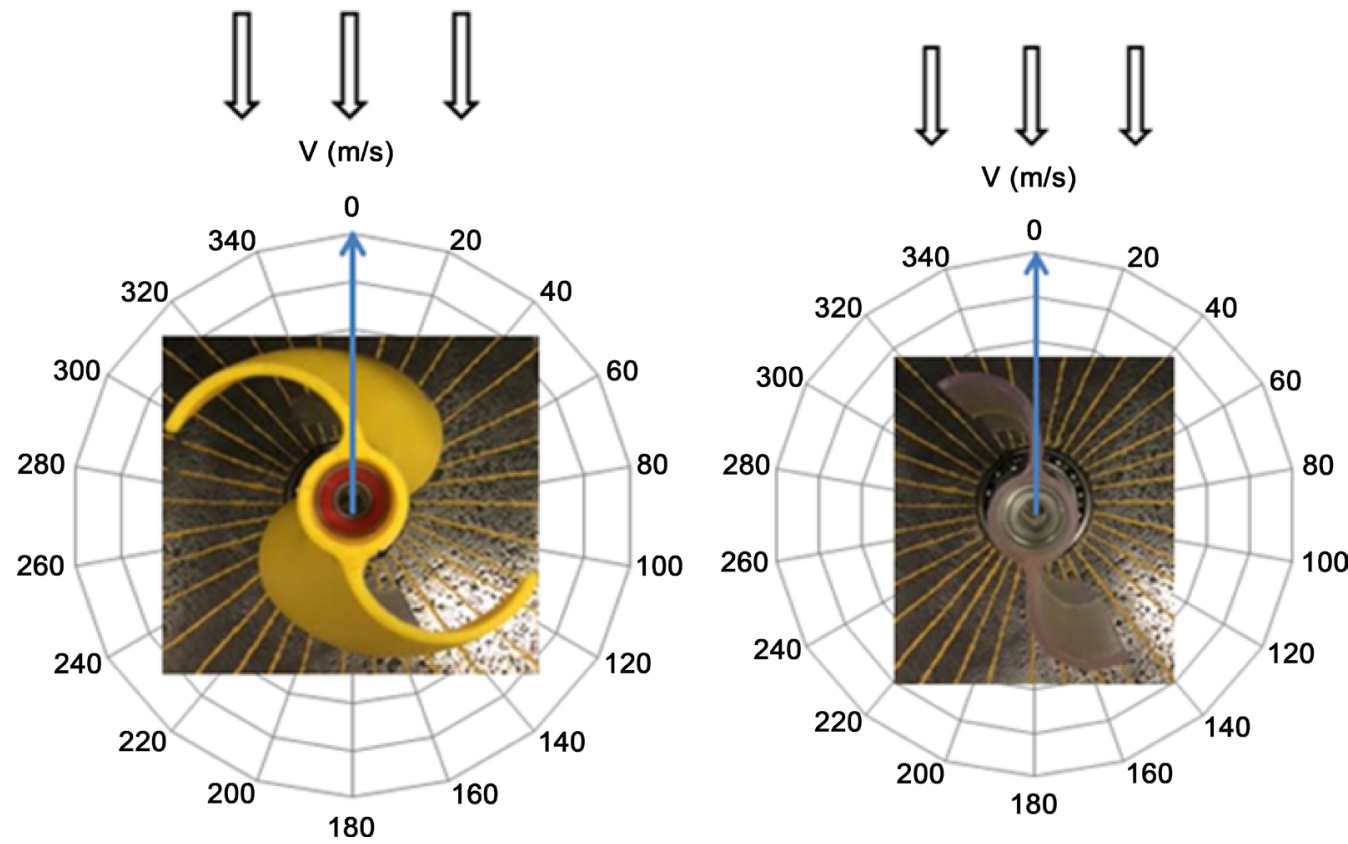

Figure 11. Helical 2 (left) and CC (right) at 0 degree angle relative to incoming wind.

of these universally used non-dimensional entities are considered for this study. The power coefficient describes the energy conversion efficiency of the turbine. Torque coefficient is a non-dimensional representation of rotor torque, which is proportional to power produced.

Using the following equations, tip-speed ratio and moment coefficient data are used to calculate the power coefficient over a range of wind velocities for each helical rotor design. In order to find the moment coefficient for each turbine, the rotor swept area must first be calculated using Equation (1),

$$
A=D H
$$

where $H$ is rotor height in $m$ and $D$ is overall diameter in $m$.

The swept area is kept consistent across all three models and used as a reference value in ANSYS Fluent for solving moment coefficients. The non-dimensional moment coefficient is calculated using Equation (2),

$$
C_{m}=\frac{T}{\frac{1}{4} \rho A D V^{2}}
$$

where $T$ is torque in N.m, $\rho$ is air density in $\mathrm{kg} / \mathrm{m}^{3}, A$ is rotor area in $\mathrm{m}^{2}$, and $V$ is air velocity in $\mathrm{m} / \mathrm{s}$. The non-dimensional term for comparing efficiency of VAWTs is the power coefficient. First the angular velocity of the rotor must be calculated by Equation (3),

$$
\omega=\frac{2 \pi N}{60}
$$

where $N$ is the measured revolutions per minute. Once the angular velocity is determined, the tip-speed ratio of the rotor is solved from Equation (4). 


$$
\lambda=\frac{\omega D}{2 V}
$$

The power coefficient is then calculated. As can be seen by Equation (5), the power coefficient is found from the product of tip-speed ratio and moment coefficient.

$$
C_{p}=\frac{P}{\frac{1}{2} \rho A V^{3}}=\frac{T \omega}{\frac{1}{2} \rho A V^{3}}=\lambda C m
$$

\section{Numerical Procedure}

In order to understand the pressure distributions and aerodynamic characteristics of the various blades in the study, numerical simulations are performed using commercial CFD software ANSYS Fluent. The CAD models are imported into ANSYS Design Modeler, and fluid regions are added to the geometry. For transient three-dimensional analysis of VAWTs, two separate fluid domains are needed for simulation [24]. A 9 inch diameter spherical enclosure around the model is used for a rotating zone. A second, stationary zone is created with a uniform box enclosure as the far-field domain. The entire three-dimensional computational domain is displayed in Figure 12.

The fluid domains are discretized using ANSYS Meshing. Each mesh consists of around 500,000 tetrahedral elements since the maximum allowable number of cells for ANSYS Fluent Academic is 512,000. The number of elements and nodes for each mesh are given in Table 1.

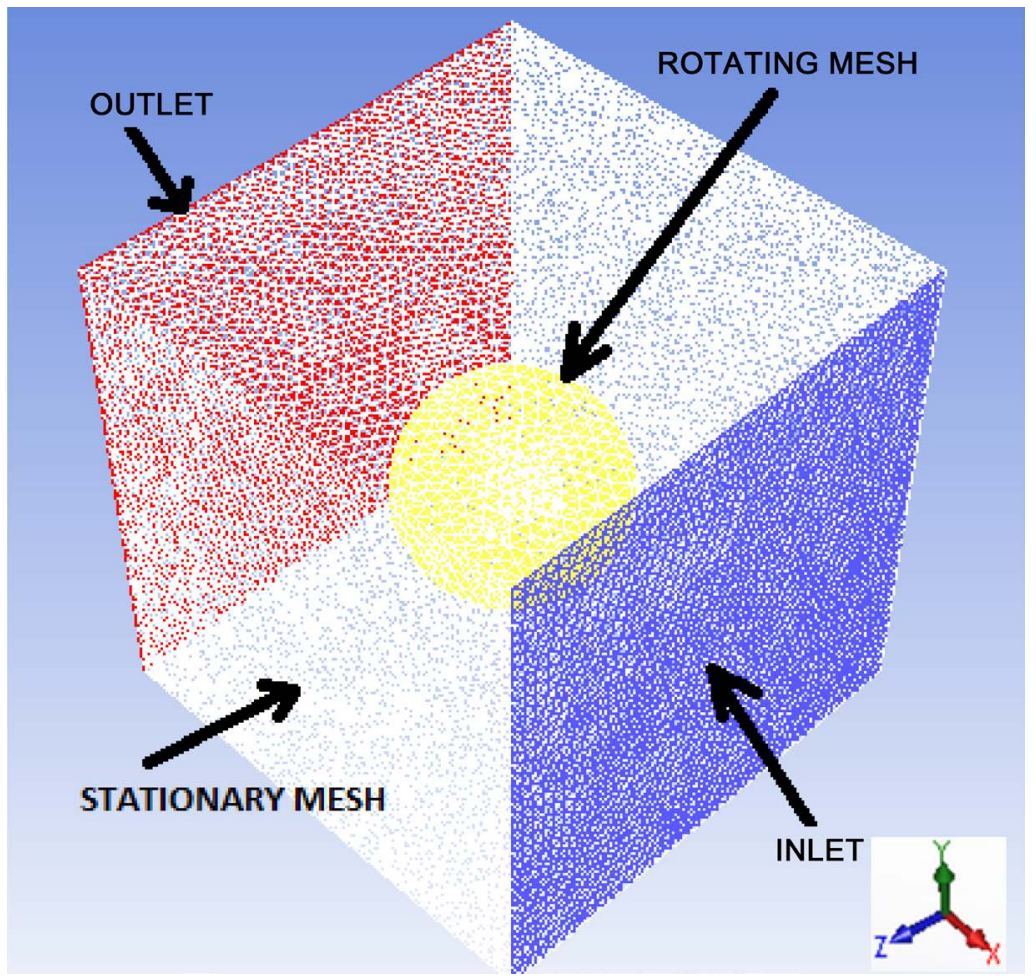

Figure 12. Three-dimensional computational domain. 
Table 1. Number of three-dimensional mesh elements and nodes.

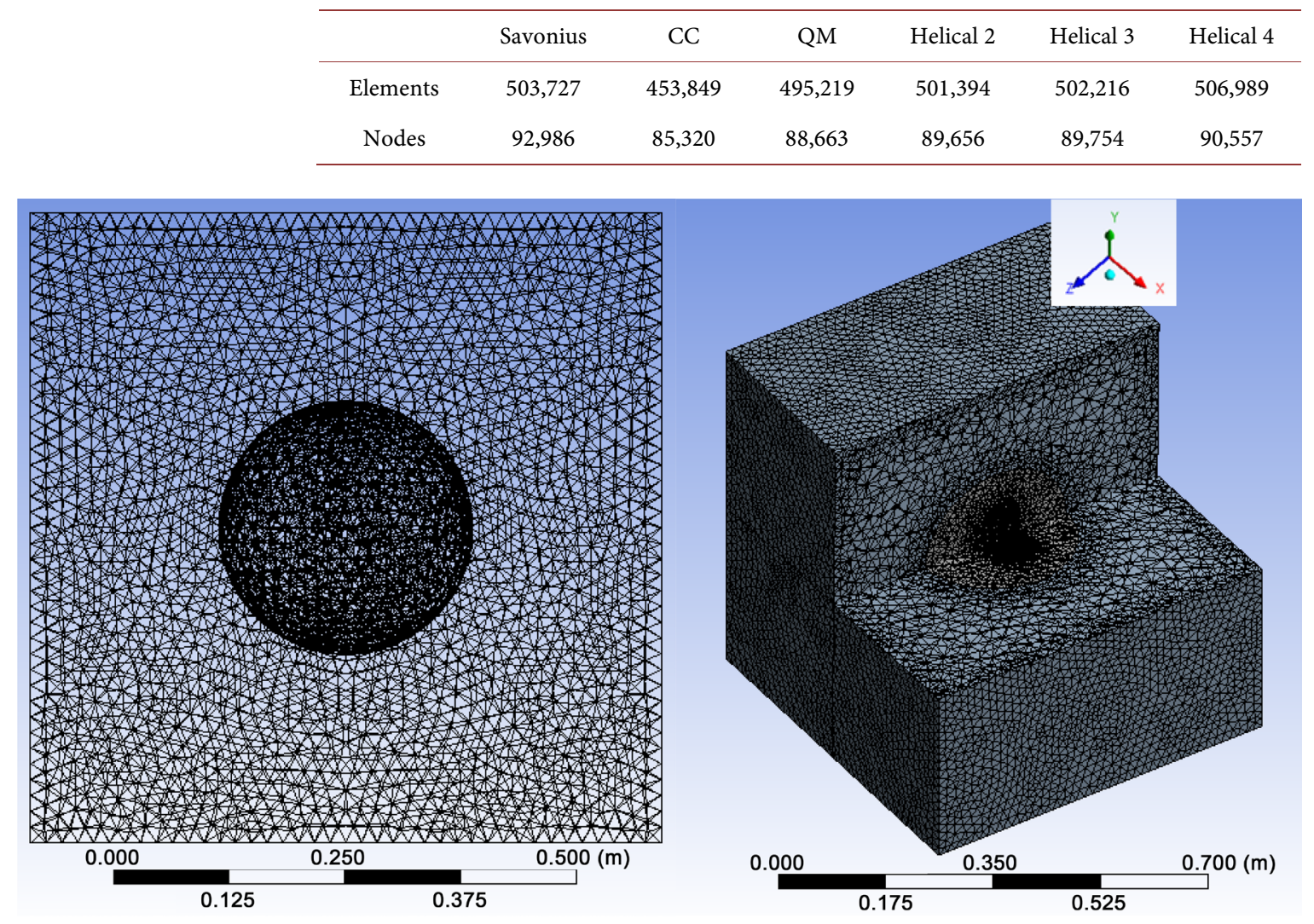

Figure 13. Top view of Savonius model mesh (left) and sectional view (right).

An example mesh is displayed in Figure 13. A top view of wireframe mesh is shown on the left, and a sectional view displaying the two separate cell zones is on the right.

The realizable k-epsilon turbulence model with standard wall functions is used for each solution. The realizable model is comparable to the RNG model with more accurate solutions [30].

The computational domain consists of a rotating zone surrounding the blades and a stationary far-field zone. A mesh interface is created between the two zones. The interface is necessary because the nodes on the boundaries of the far-field and rotational zones are intentionally non-conformal. The interface pairs these so that interpolation can occur, and fluid may pass into and out of the rotating region. For each case, a static simulation with moving reference frame (MRF) and a dynamic sliding mesh model (SMM) are completed. The rotation is first defined using the steady-state solver with MRF, and the simulation is then solved in a transient manner using a sliding mesh motion. The converged static result from the MRF simulation is used to initialize the transient SMM solver. Convergence criteria are kept consistent throughout the study requiring all 5 residuals to decrease to a value of 1e-03. For the transient solver; coefficients of moment $(\mathrm{Cm})$ are monitored over time with accurate reference values. Time step size is dependent on the RPM value for each case. Time steps are cal- 
culated to account for every 10 degrees of model rotation. For 2 full rotations, 72 time steps per simulation are run with 20 iterations per time step.

\subsection{Boundary Conditions}

Boundary conditions for the simulations are taken from experimental data. These include air velocity inlet speed and corresponding rotational speed of the blades. The pressure outlet is kept at constant atmospheric pressure. The blade walls are given a no slip condition and zero rotational velocity relative to the sliding mesh zone (equal to the rotating fluid domain).

\subsection{Turbulence Model}

The realizable k-epsilon model is used with the SIMPLE segregated algorithm [30]. For improved accuracy, the double precision option is selected. The turbulence kinetic energy $(k)$ and its dissipation rate (epsilon) for the realizable $\mathrm{k}$-epsilon model are obtained from the following transport equations:

$$
\frac{\partial}{\partial t}(\rho k)+\frac{\partial}{\partial x_{j}}\left(\rho k u_{j}\right)=\frac{\partial}{\partial x_{j}}\left[\left(u+\frac{\mu_{t}}{\sigma_{k}}\right) \frac{\partial k}{\partial x_{j}}\right]+P_{k}+P_{b}-\rho \epsilon-Y_{m}+S_{k}
$$

and

$\frac{\partial}{\partial t}(\rho \epsilon)+\frac{\partial}{\partial x_{j}}\left(\rho \epsilon u_{j}\right)=\frac{\partial}{\partial x_{j}}\left[\left(u+\frac{\mu_{t}}{\sigma_{\epsilon}}\right) \frac{\partial \epsilon}{\partial x_{j}}\right]+\rho C_{1} S \epsilon-\rho C_{2} \frac{\epsilon^{2}}{k+\sqrt{v \epsilon}}+C_{1 \epsilon} \frac{\epsilon}{k} C_{3 \epsilon} P_{b}+S_{\epsilon}$

where

$$
C_{1}=\max \left[0.43, \frac{\eta}{\eta+5}\right], \eta=S \frac{k}{\epsilon}, S=\sqrt{2 S_{i j} S_{i j}}
$$

In these equations, $P_{K}$ represents generation of turbulence kinetic energy due to mean velocity gradients, and $P_{b}$ is generation of turbulence kinetic energy due to buoyancy [30].

\section{Findings of the Study}

\subsection{Initial Simulations of Straight-Bladed Models}

A 3D CFD analysis is conducted for the SAV, CC, and QM models to study the effects of the different geometries on the amount of torque generated. Rotational speed of the models is kept constant at 275 RPM for all models and all tip-speed ratios (TSRs) in this part of the study. Only inlet velocity is varied with speeds of 3,5 , and $7 \mathrm{~m} / \mathrm{s}$. The increasing wind speeds resulted in tip-speed ratios of 0.51 , 0.31 , and 0.22 . The following results contain the transient moment coefficient monitors for the simulations with constant rotational speed.

The SAV model is used for obtaining baseline results, to which the new designs may be compared. At $3 \mathrm{~m} / \mathrm{s}$ inlet velocity, the maximum $\mathrm{Cm}$ is 0.134 with an average of 0.029 . At $5 \mathrm{~m} / \mathrm{s}$ the maximum $C m$ is 0.560 with an average of 0.145 . At $7 \mathrm{~m} / \mathrm{s}$ the maximum $\mathrm{Cm}$ is 1.248 with an average of 0.315 . The $C m$ vs. time graph for SAV is displayed in Figure 14 . At $7 \mathrm{~m} / \mathrm{s}$ inlet velocity, the SAV 
model experiences negative torque in two ranges of operation: 0 - 55 degrees ( 0 $0.039 \mathrm{~s})$ and 175 - 230 degrees (0.105 - $0.138 \mathrm{~s})$.

The CC rotor experiences higher maximum and average moment coefficients than SAV at all 3 tested tip-speed ratios. The maximum $C m$ achieved is 1.390 at $7 \mathrm{~m} / \mathrm{s}$ inlet velocity. Results are displayed in Figure 15. At the maximum inlet velocity, the CC model also experiences negative torque in two ranges of operation: 5 - 45 degrees (0.003 - $0.027 \mathrm{~s})$ and 185 - 235 degrees $(0.111-0.141 \mathrm{~s})$. The

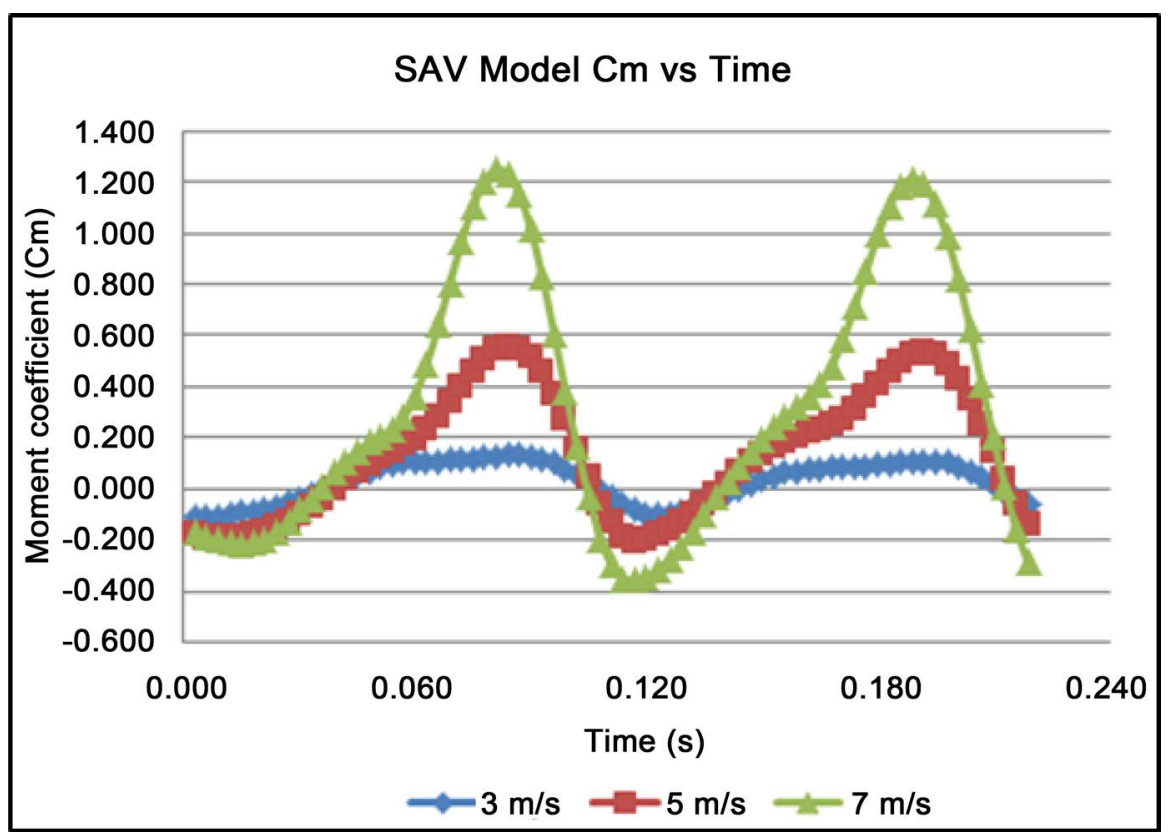

Figure 14. Transient monitor of moment coefficient $(\mathrm{Cm})$ for SAV model with wind speeds of $3 \mathrm{~m} / \mathrm{s}, 5 \mathrm{~m} / \mathrm{s}$, and $7 \mathrm{~m} / \mathrm{s}$.

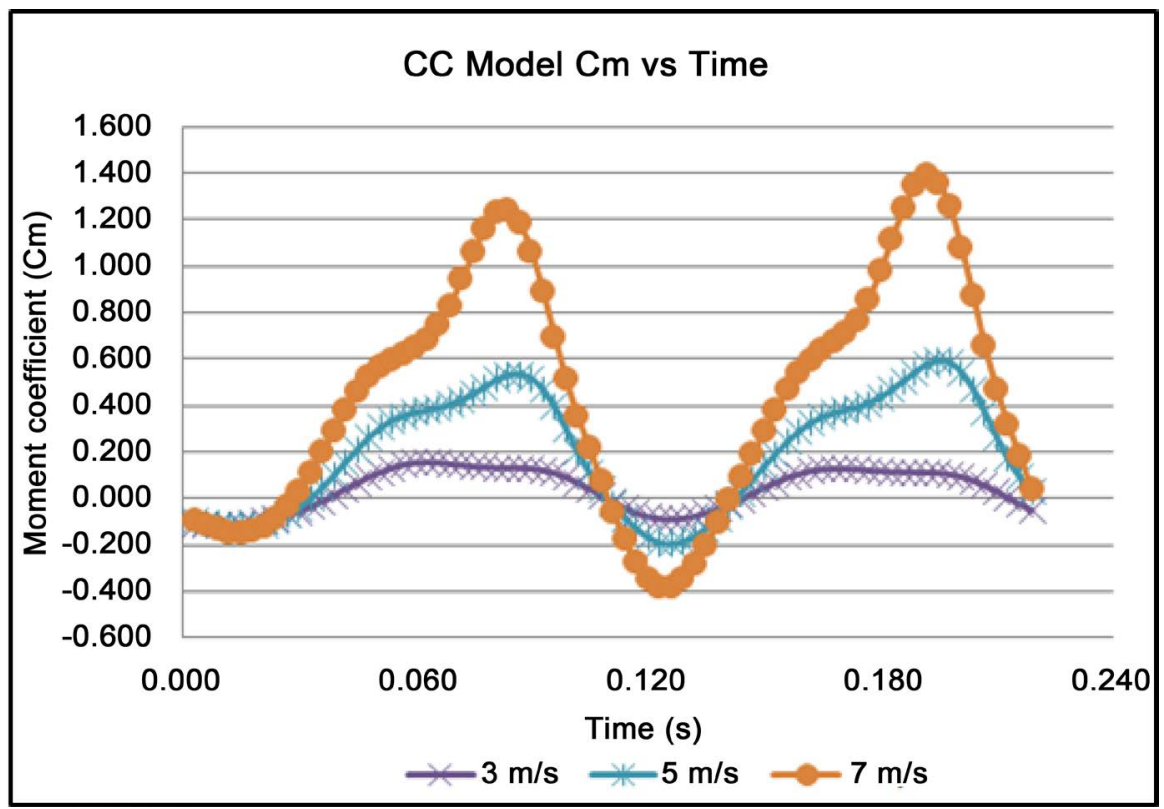

Figure 15. Transient monitor of moment coefficient $(\mathrm{Cm})$ for $\mathrm{CC}$ model with wind speeds of $3 \mathrm{~m} / \mathrm{s}, 5 \mathrm{~m} / \mathrm{s}$, and $7 \mathrm{~m} / \mathrm{s}$. 
total range of negative torque at $7 \mathrm{~m} / \mathrm{s}$ wind velocity is 20 degrees more narrow, compared to the SAV model.

The QM model outperforms both the CC and SAV models in terms of maximum moment coefficient at 5 and $7 \mathrm{~m} / \mathrm{s}$ inlet velocities as shown in Figure 16 . At the highest tested TSR, QM enjoys the best performance in the constant RPM numerical study. With wind velocity set at $7 \mathrm{~m} / \mathrm{s}, \mathrm{QM}$ achieves a maximum moment coefficient $(\mathrm{Cm})$ of 1.474 with an average of 0.455 . The range of negative torques at this inlet velocity is the same as that of the CC model: 5 - 45 degrees (0.003 - $0.027 \mathrm{~s})$ and 185 - 235 degrees (0.111 - $0.141 \mathrm{~s})$.

A comparison of $\mathrm{Cm}$ data for each design is presented in Figures 17-19 at

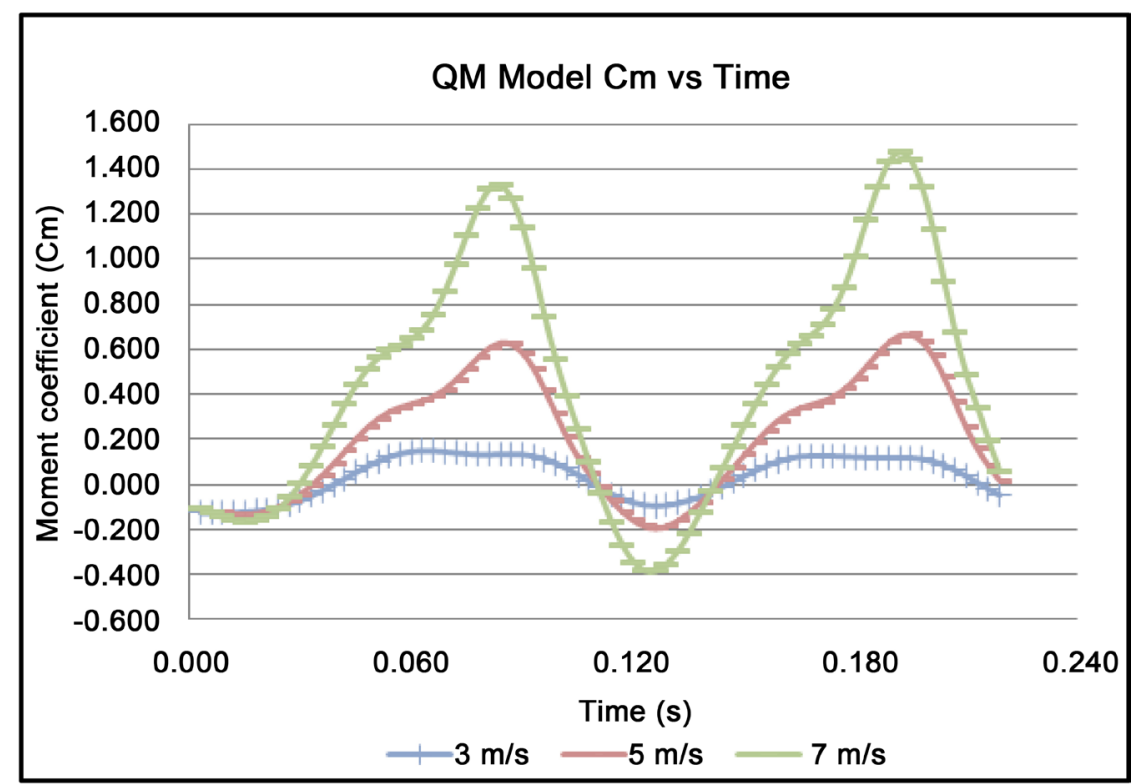

Figure 16. Transient monitor of moment coefficient $(\mathrm{Cm})$ for $\mathrm{QM}$ model with wind speeds of $3 \mathrm{~m} / \mathrm{s}, 5 \mathrm{~m} / \mathrm{s}$, and $7 \mathrm{~m} / \mathrm{s}$.

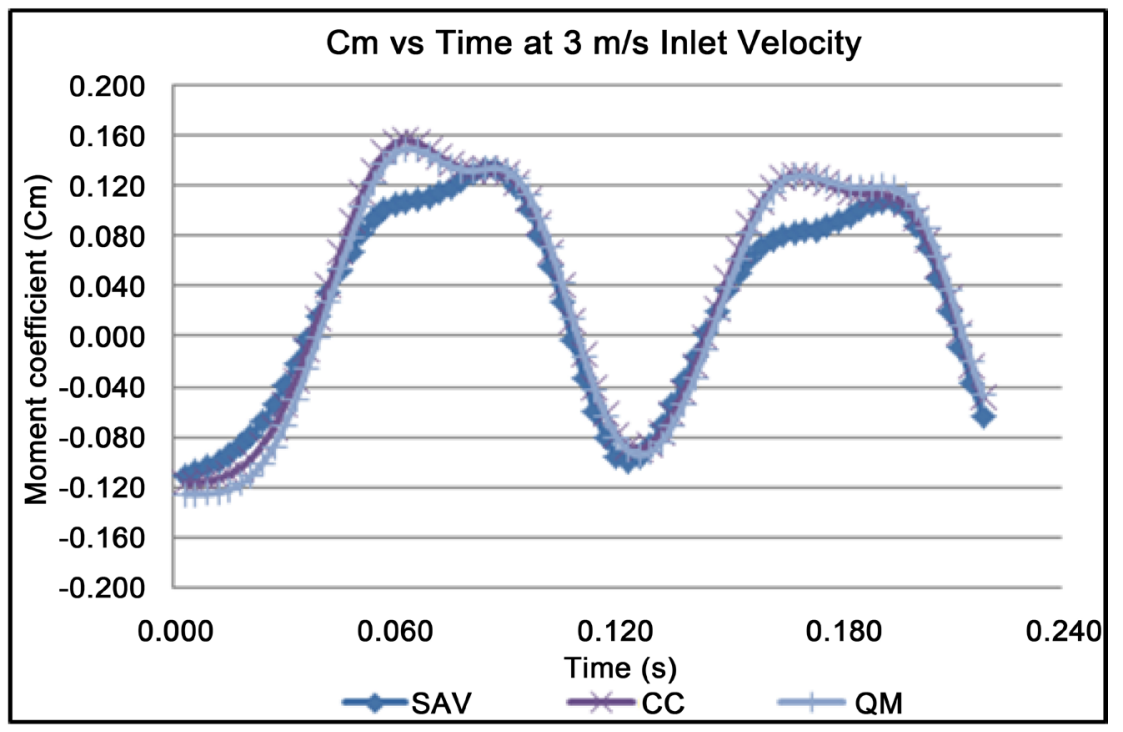

Figure 17. Cm Comparison of 3 models at $3 \mathrm{~m} / \mathrm{s}$ inlet velocity. 


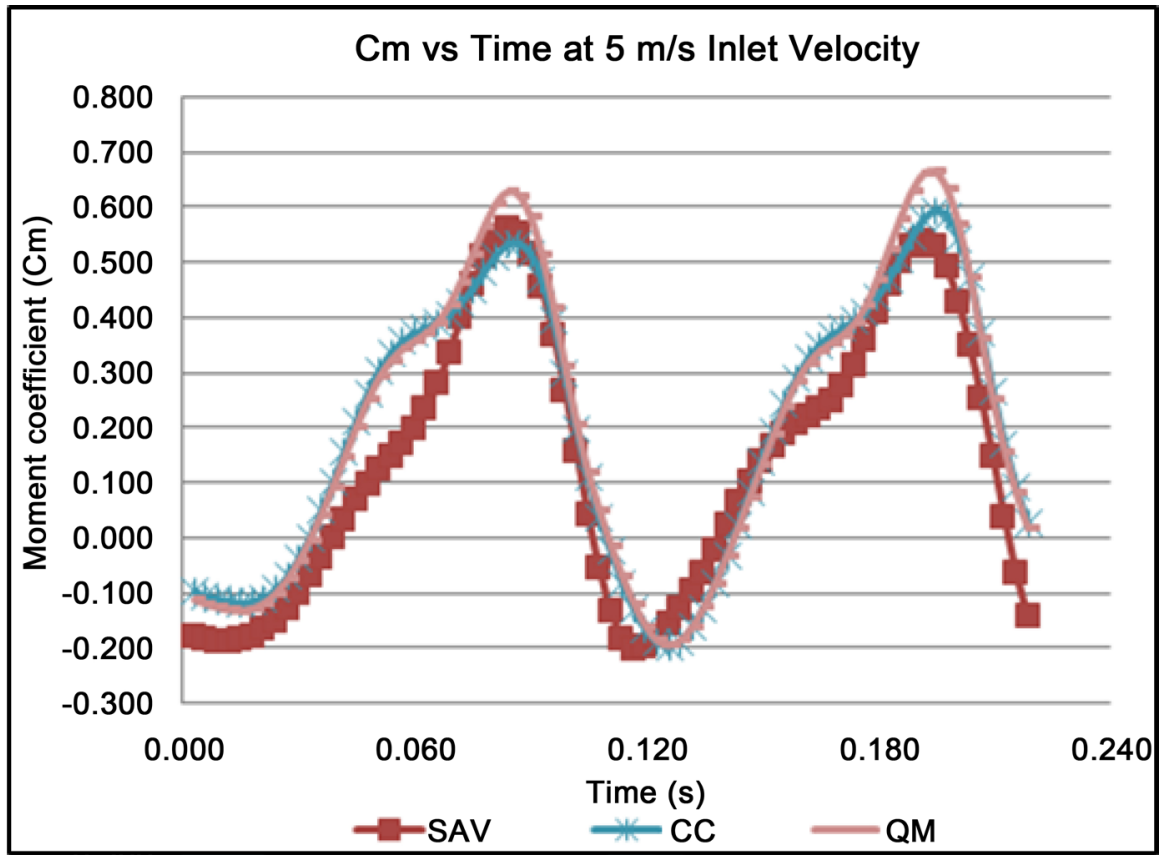

Figure 18. Cm Comparison of 3 models at $5 \mathrm{~m} / \mathrm{s}$ inlet velocity.

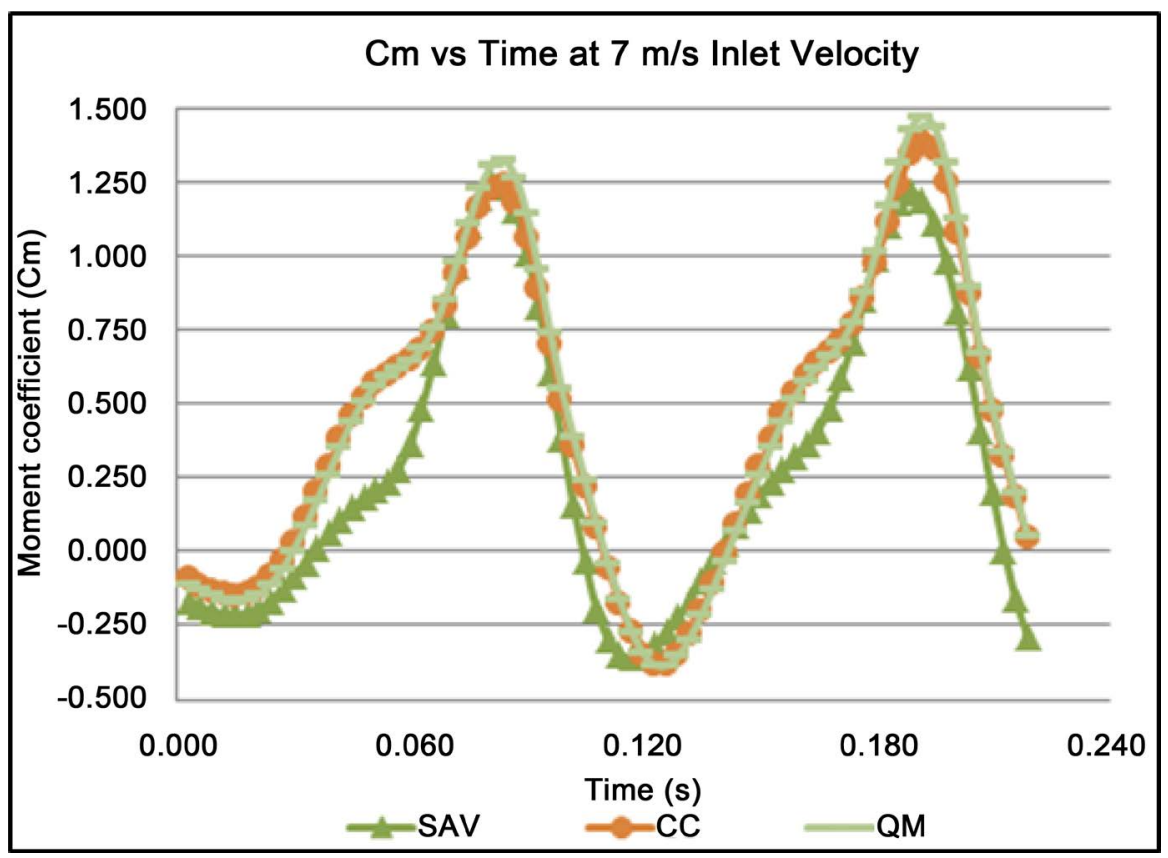

Figure 19. Cm Comparison of 3 models at $7 \mathrm{~m} / \mathrm{s}$ inlet velocity.

inlet velocities of 3,5 , and $7 \mathrm{~m} / \mathrm{s}$, respectively.

At highest simulated wind speed, SAV experiences negative torque from 0-55 degrees and 180 - 235 degrees. QM and CC both have negative torque ranges of 5 - 45 degrees and 185 - 235 degrees. As can be seen in the comparison figures, a large difference in moment coefficient between the new designs and the traditional SAV model occurs at about 0.06 seconds (100 degrees) for each tested wind speed. CFD post-processing within the ANSYS Fluent software is used to 
investigate the aerodynamic characteristics at this time step. Air pressure contours surrounding the blades, air velocity vectors, and blade wall pressures are displayed in Tables 2-5 for the $5 \mathrm{~m} / \mathrm{s}$ wind velocity simulations.

The SAV model experiences higher pressure at the front of the blades. CC and QM experience more negative pressure on the back side of the blade. These two conditions result in greater torque for the CC and QM models.

The air velocity vectors for each model are shown in Table 3. Compared to the SAV model, higher velocities are present on the back side of the retreating

Table 2. Air pressure contours surrounding blades at $0.06 \mathrm{~s}$.

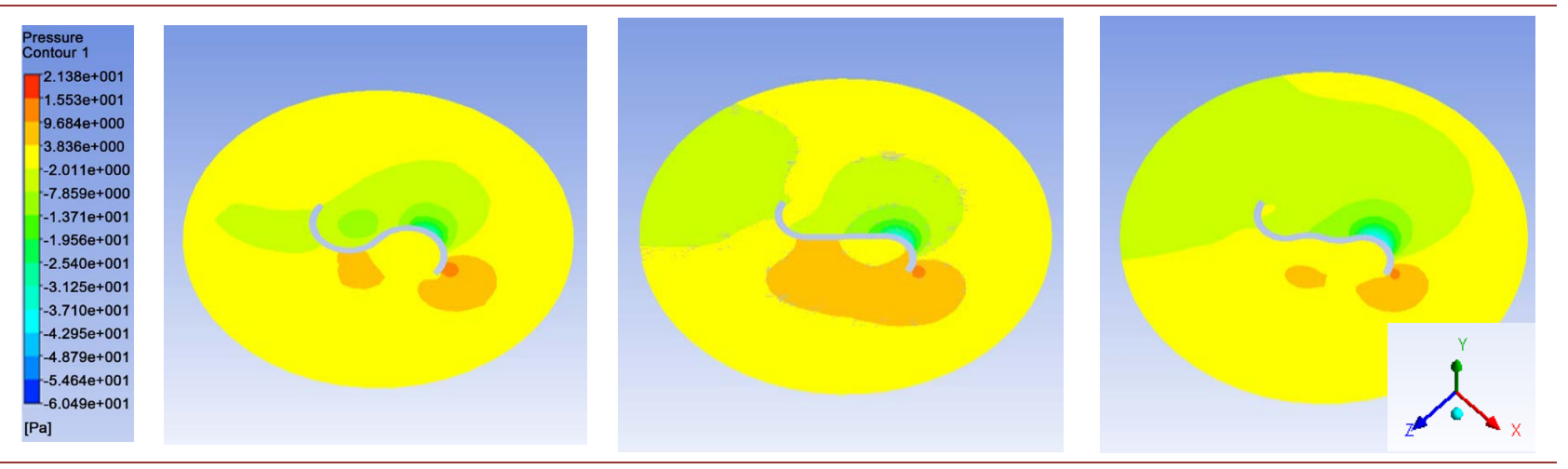

Table 3. Air velocity vectors surrounding blades at $0.06 \mathrm{~s}$.

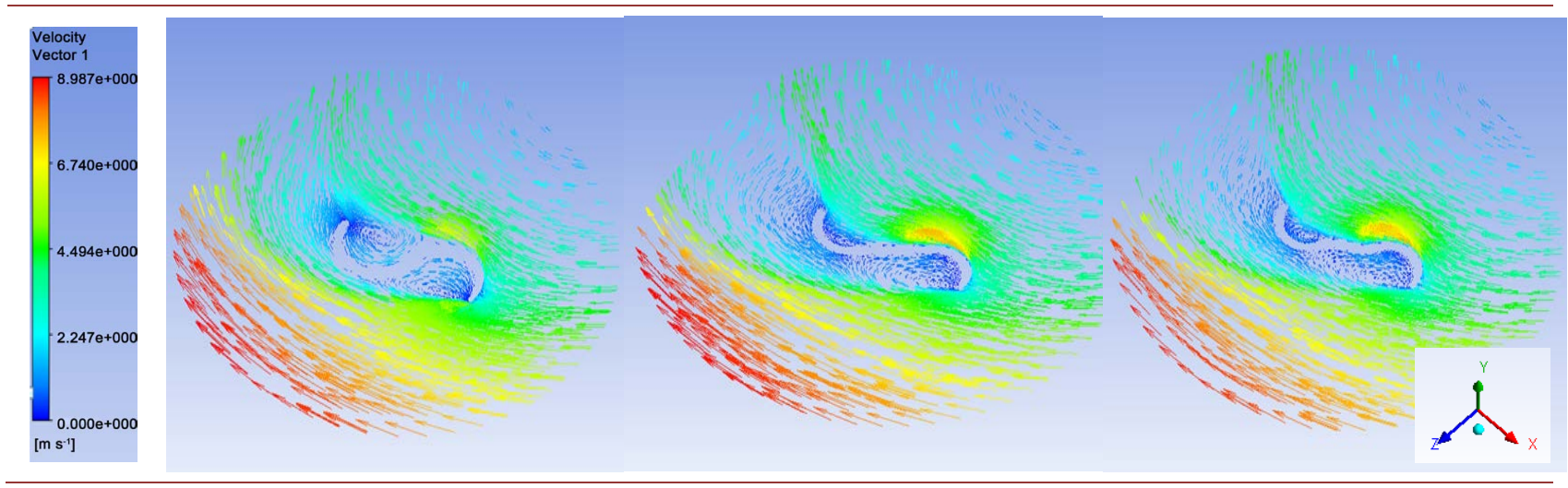

Table 4. Pressure contours on the backside of retreating blades at $0.06 \mathrm{~s}$.

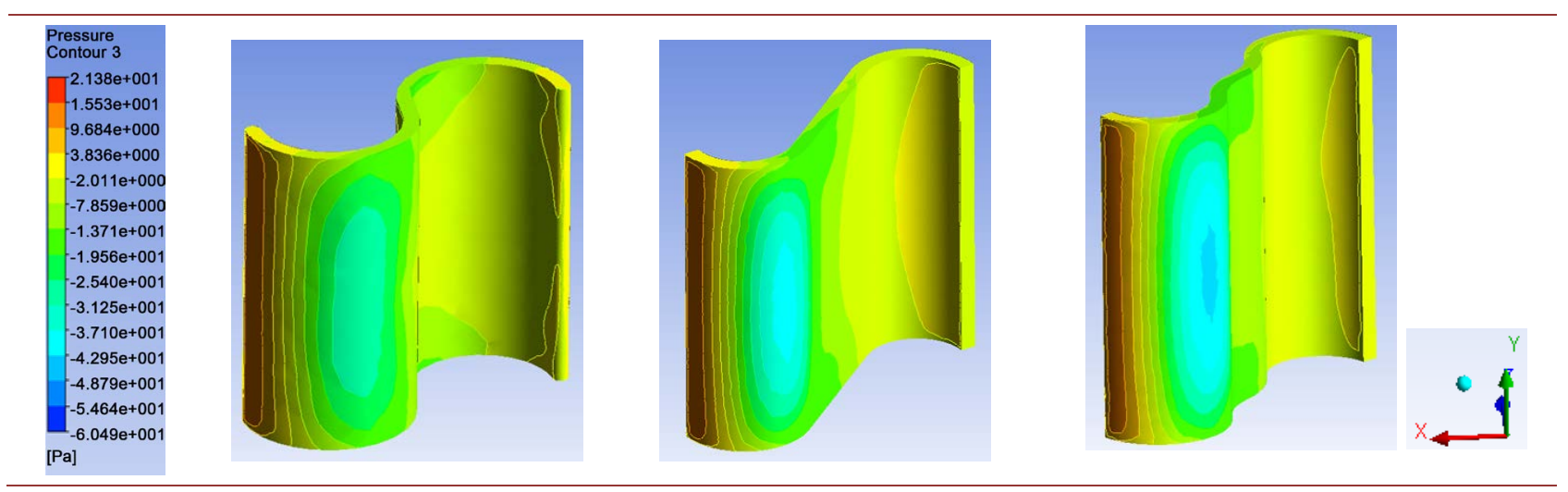


blade for the new designs. This results in a greater pressure difference and larger moment coefficient.

The negative pressures on the reverse side of the retreating blades at $0.06 \mathrm{~s}$ are presented as 3D pressure contours in Table 4.

Using calculated tip-speed ratio and moment coefficient data from ANSYS, the power coefficient $(C P)$ of each case is determined. Maximum and average power coefficients for the 9 dynamic simulations in this study are presented in Table 5.

A graph of maximum $C p$ vs. TSR for the 3 models is displayed in Figure 20. For all 3 blade geometries, the highest efficiency is achieved at lower tip-speed ratios. This is expected because RPM was kept constant even with increasing inlet wind velocities. This also explains the high values of power coefficient. Although these are not realistic operating conditions for these models, the results

Table 5. Average and maximum Cp results of 3 models for constant RPM numerical study.

\begin{tabular}{ccccccc}
\hline Model & $V(\mathrm{~m} / \mathrm{s})$ & TSR & Avg $C m$ & Max $C m$ & $\operatorname{Avg} C p$ & Max $C p$ \\
\hline SAV & 3 & 0.512 & 0.029 & 0.134 & 0.015 & 0.068 \\
SAV & 5 & 0.307 & 0.142 & 0.560 & 0.043 & 0.172 \\
SAV & 7 & 0.219 & 0.315 & 1.248 & 0.069 & 0.274 \\
CC & 3 & 0.512 & 0.041 & 0.157 & 0.021 & 0.080 \\
CC & 5 & 0.307 & 0.203 & 0.594 & 0.062 & 0.182 \\
CC & 7 & 0.219 & 0.442 & 1.390 & 0.097 & 0.305 \\
QM & 3 & 0.512 & 0.037 & 0.150 & 0.019 & 0.077 \\
QM & 5 & 0.307 & 0.214 & 0.664 & 0.066 & 0.204 \\
QM & 7 & 0.219 & 0.455 & 1.474 & 0.100 & 0.323 \\
\hline
\end{tabular}

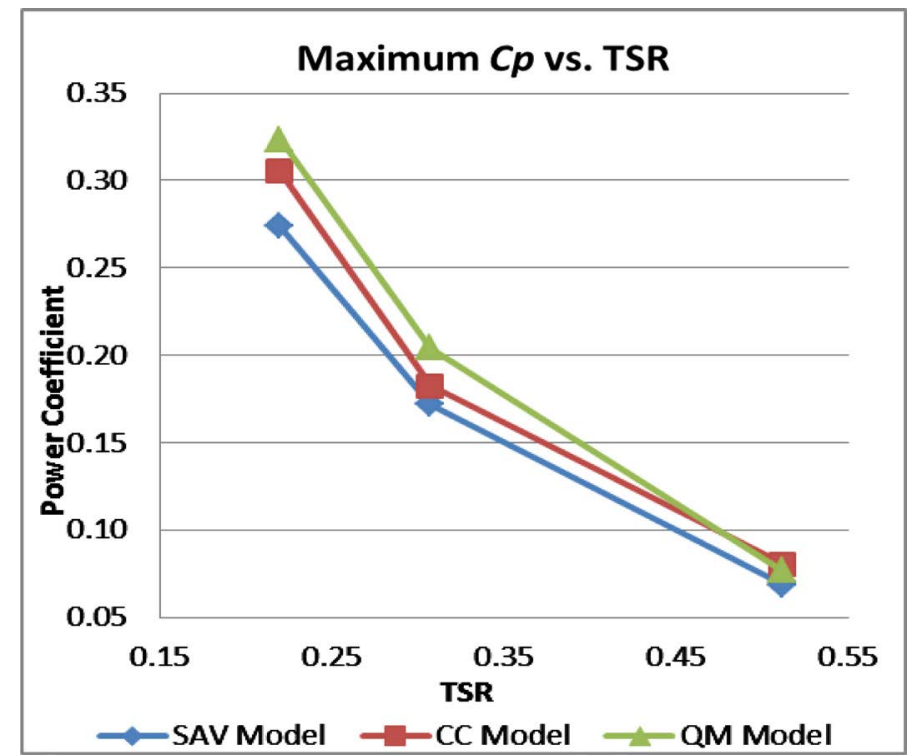

Figure 20. Max power coefficient vs. tip-speed ratio for 3 models in constant RPM study. 
in this section are only used to compare the aerodynamic performance of the different blade geometries. Both of the new designs achieve higher power coefficients than the semicircle Savonius blade design. Compared to the SAV model, CC achieves an $11.38 \%$ increase in maximum efficiency and a $40.07 \%$ increase in average efficiency. The highest efficiency observed in the study of $32.35 \%$ was the QM model at TSR 0.219. This was an increase in power coefficient of $18.10 \%$, compared to the standard SAV model.

Both QM and CC model geometries effectively produce a center of pressure on the blades further from the axis of rotation. This change in blade geometry increases the applied torque on the turbine shaft while maintaining the same swept area as the conventional Savonius model.

\subsection{Experimental RPM}

Experimental RPM data is collected for all 6 VAWT models. The models are free to rotate with no applied load in this test. RPM vs. wind velocity data is presented in Figure 21.

From the graph, it can be seen that the Helical 3 and Helical 2 models achieve the best self-starting characteristics in low wind speed conditions. Helical 3 begins rotation at $1.4 \mathrm{~m} / \mathrm{s}$ with $35 \mathrm{RPM}$, while Helical 2 starts rotating at $1.5 \mathrm{~m} / \mathrm{s}$ with 45 RPM. SAV has the worst self-starting capability in the study, beginning rotation at wind velocity of $2.3 \mathrm{~m} / \mathrm{s}$. At higher wind speeds, Helical 3 achieves the fastest rotation of all 6 models. Helical 2 and Helical 3 both record significantly higher RPM than the other 4 models over the entire tested range of wind speeds.

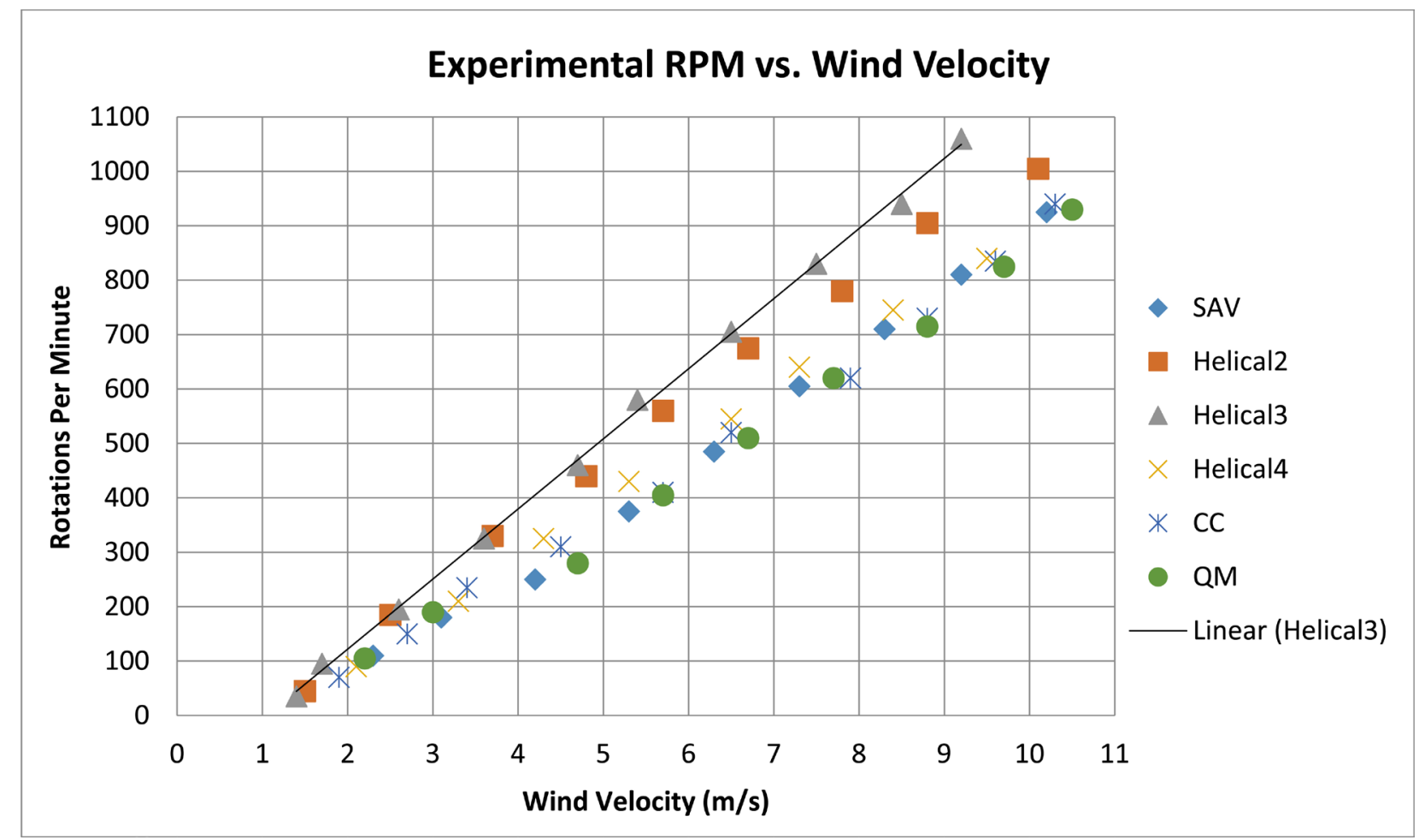

Figure 21. Experimental RPM vs. wind velocity for 6 models with no load. 


\subsection{Experimental Torque}

Each model is tested under varying wind conditions to determine the torque generated at every 10 degrees of model rotation. The reactional torque meter is used for the collection of experimental torque data. The torque data recorded for all 6 models are contained in Figures 22-27. The straight-bladed models, SAV, $\mathrm{CC}$, and QM, all experience negative torque in 2 ranges of operation.

As can be seen in Figures 25-27, all of the helical models experience positive torque for each angle of rotation. The Helical 2 and Helical 3 models generate significantly more torque than the Helical 4 model at equivalent wind speeds.

\subsection{Experimental Coefficients of Moment and Power}

The measured wind velocity, RPM, and torque data from the wind tunnel experiments are used to calculate the coefficient of moment and power for each turbine model. Moment coefficient is found from Equation (2), and power coefficient is found from Equation (5) in the methodology. Graphs of experimental moment coefficient vs. angle of rotation are displayed in Figures 28-33.

In order to compare the experimental efficiencies of the models, experimental power coefficient vs. tip-speed ratio for the 6 designs are plotted together in Figure 34.

The Helical 2 model achieves the highest experimental power coefficient of 0.109 at a tip-speed ratio of 0.497. Maximum $C p$ for Helical 3 is 0.102 at tip-speed ratio 0.623 . The 90 degree helical models with 2 and 3 blades perform significantly better than the other four models in the study.

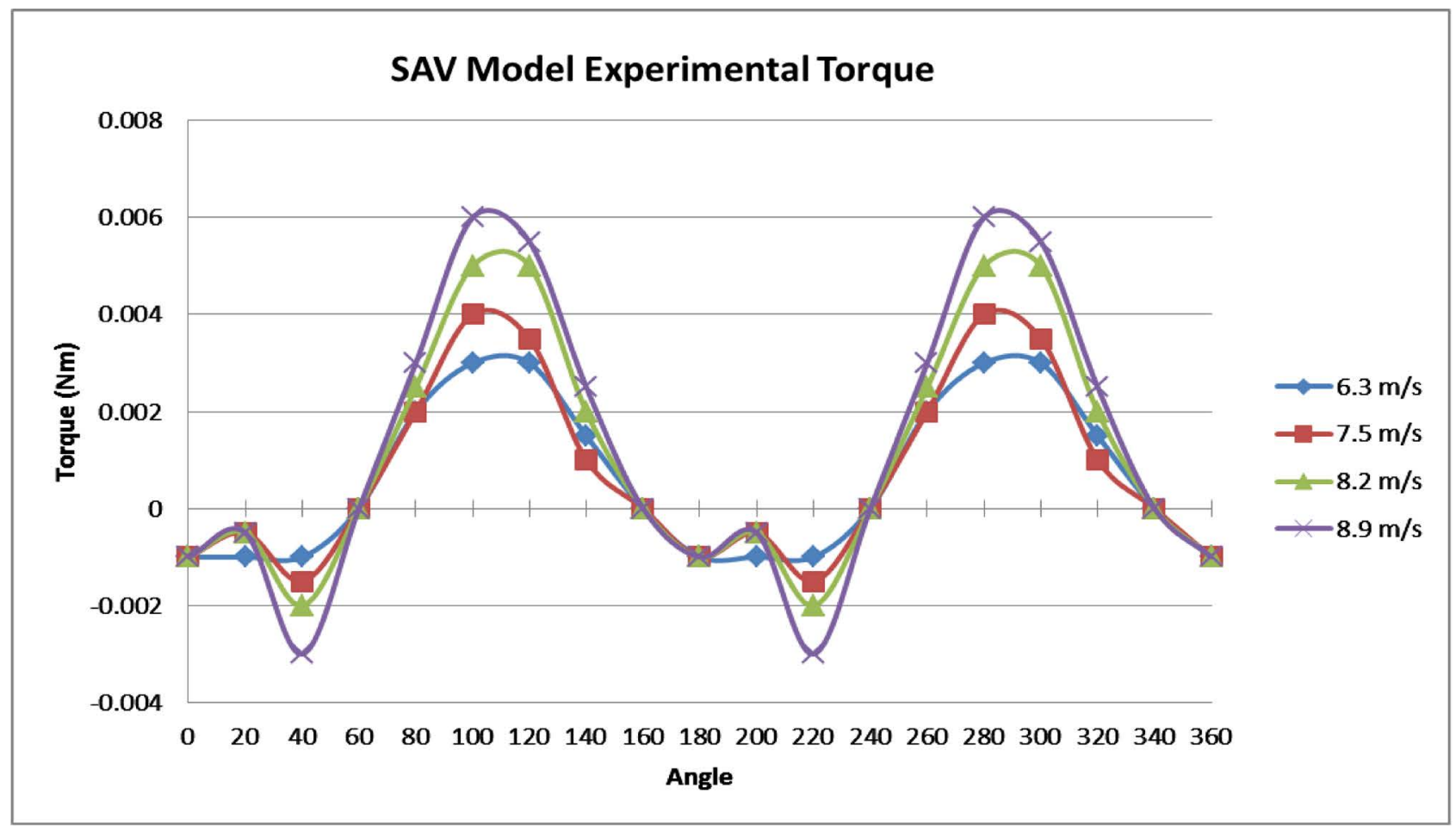

Figure 22. SAV model experimental torque data. 


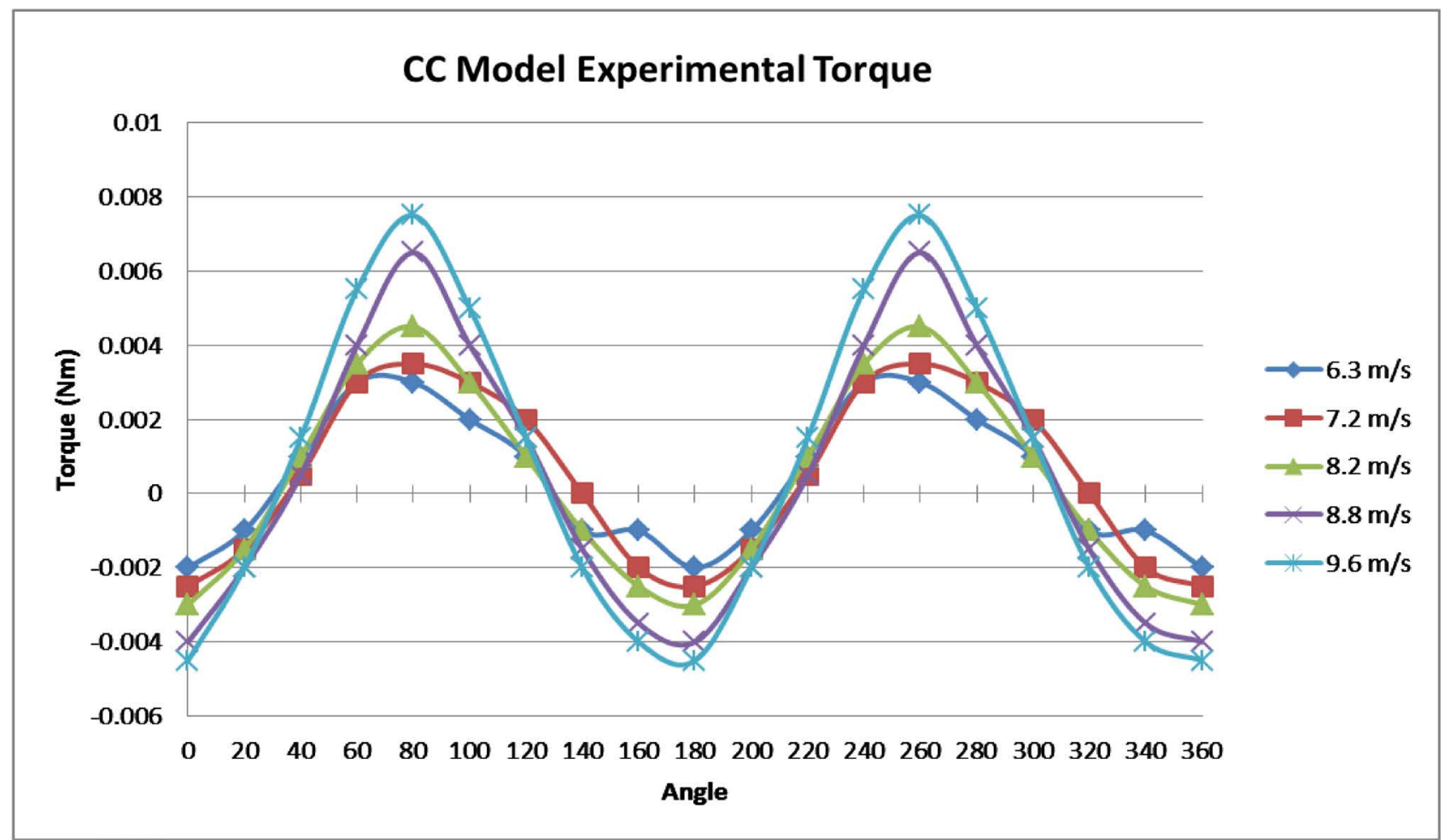

Figure 23. CC model experimental torque data.

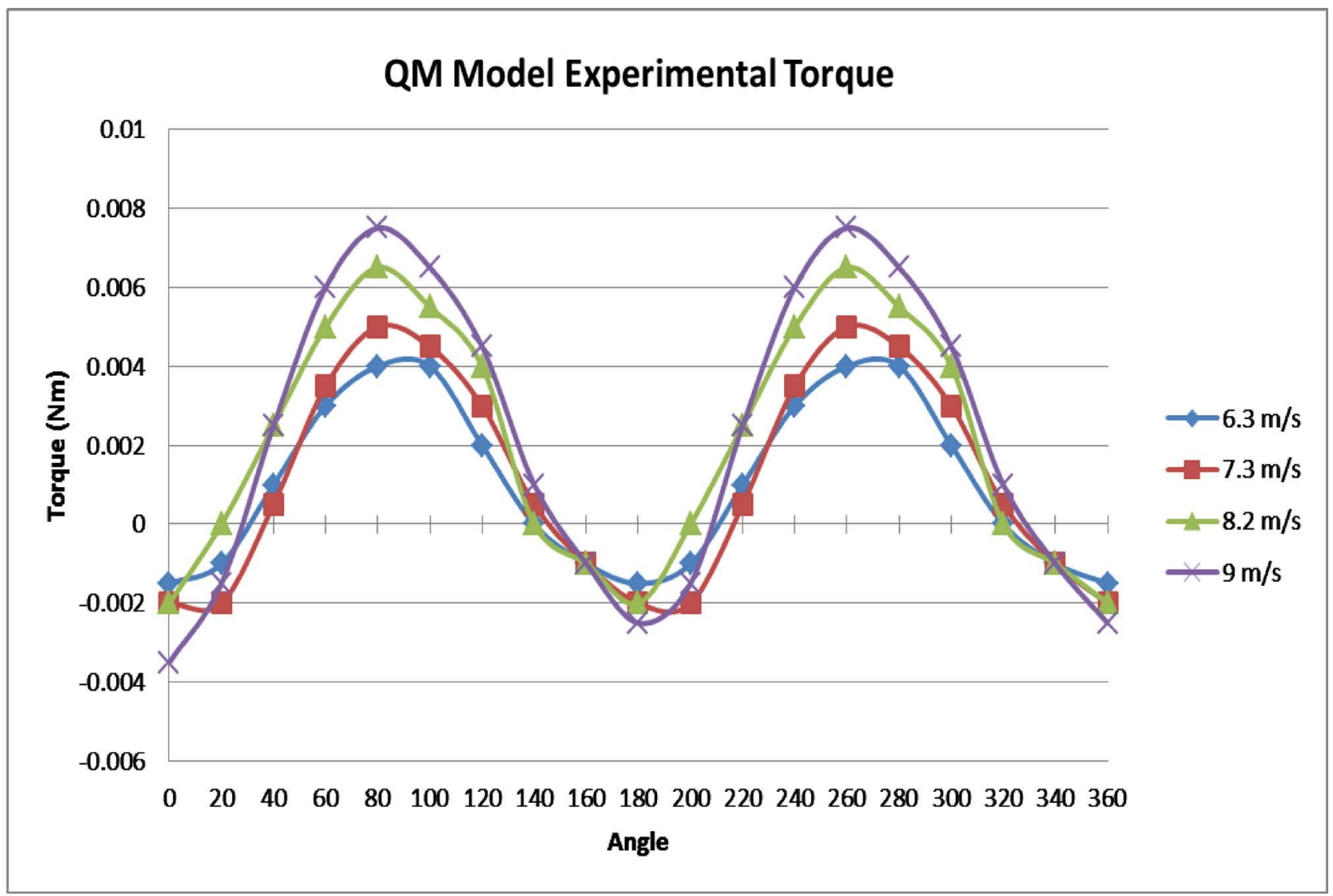

Figure 24. QM model experimental torque data. 


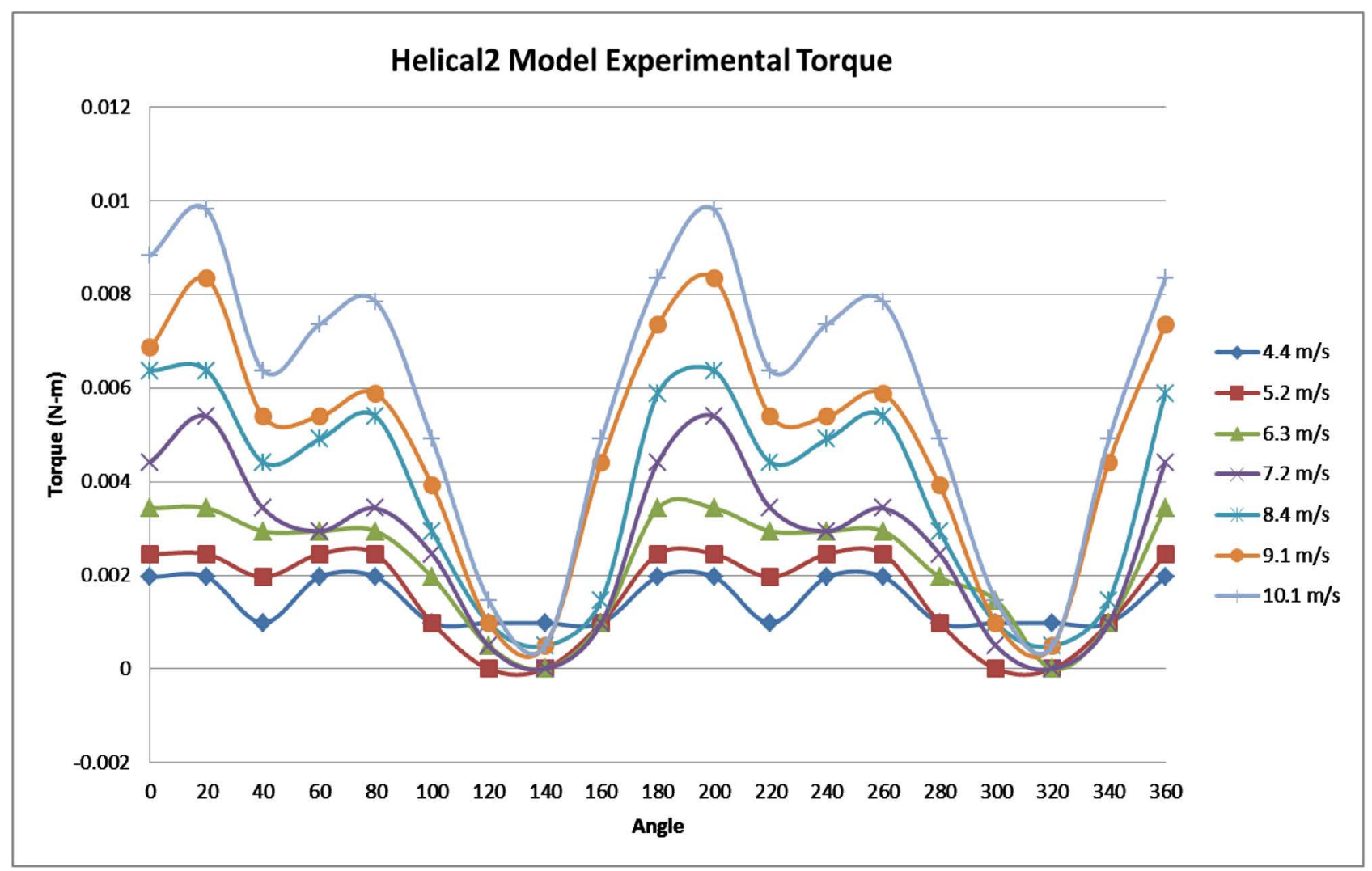

Figure 25. Helical 2 model experimental torque data.

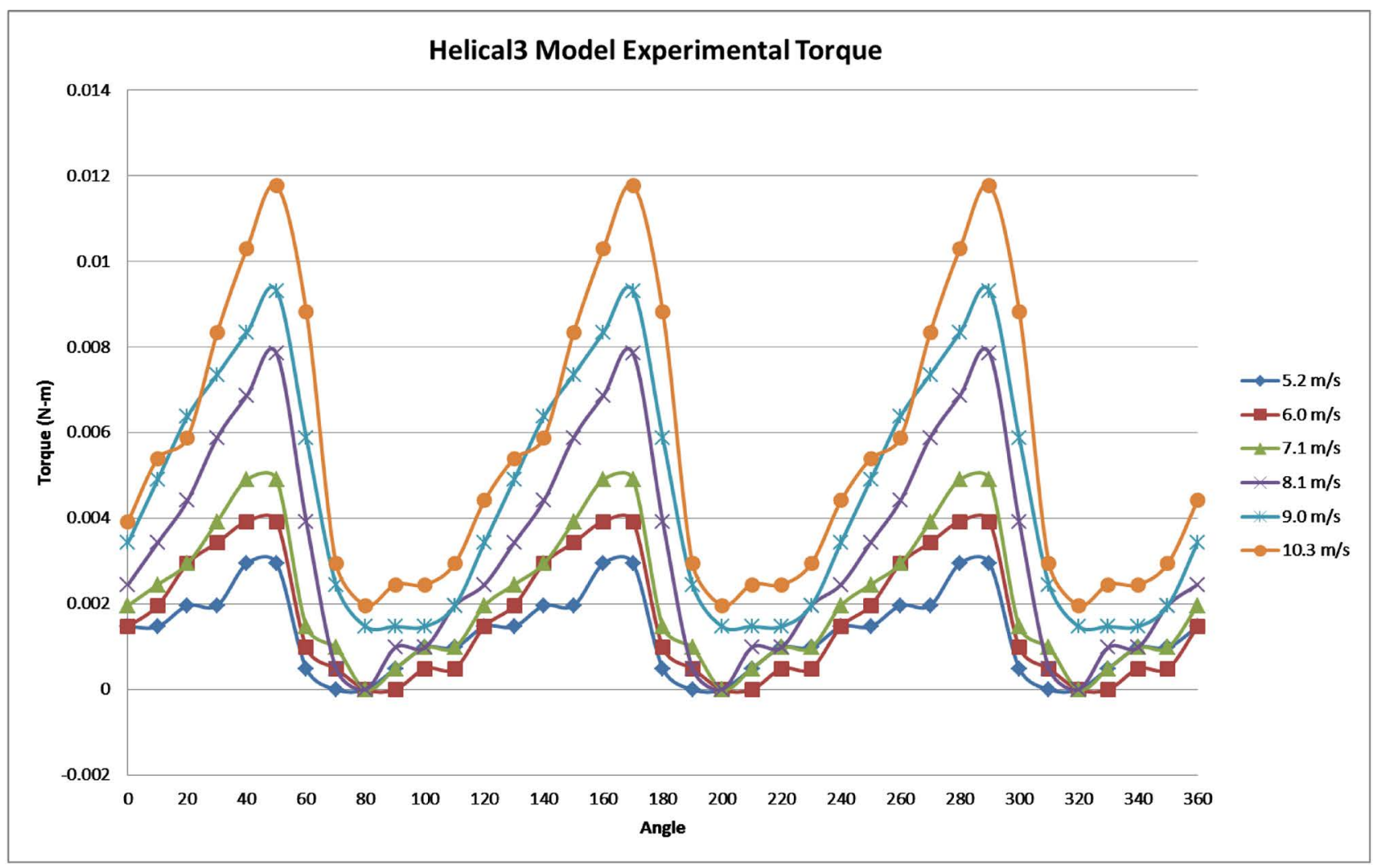

Figure 26. Helical 3 model experimental torque data. 


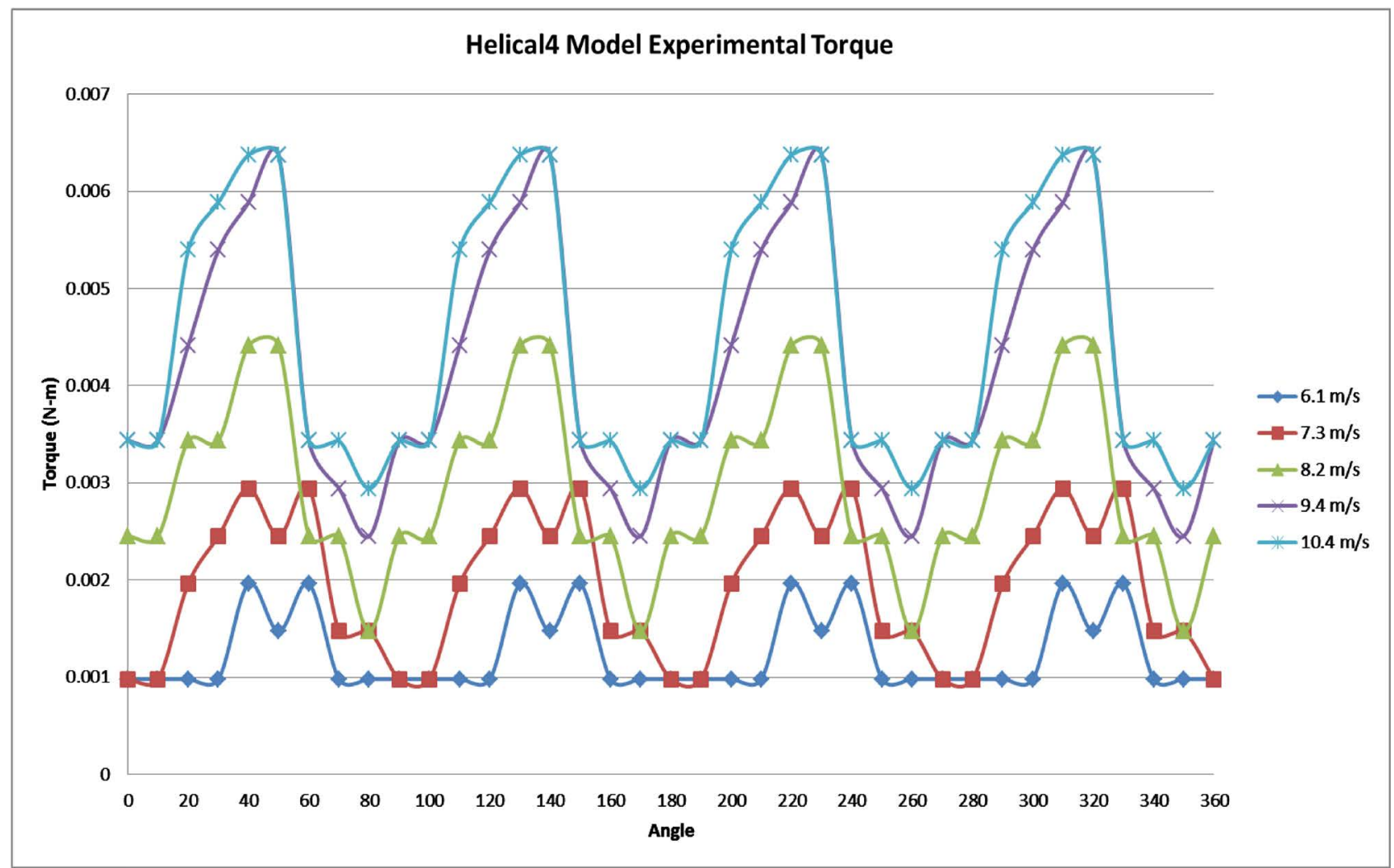

Figure 27. Helical 4 model experimental torque data.

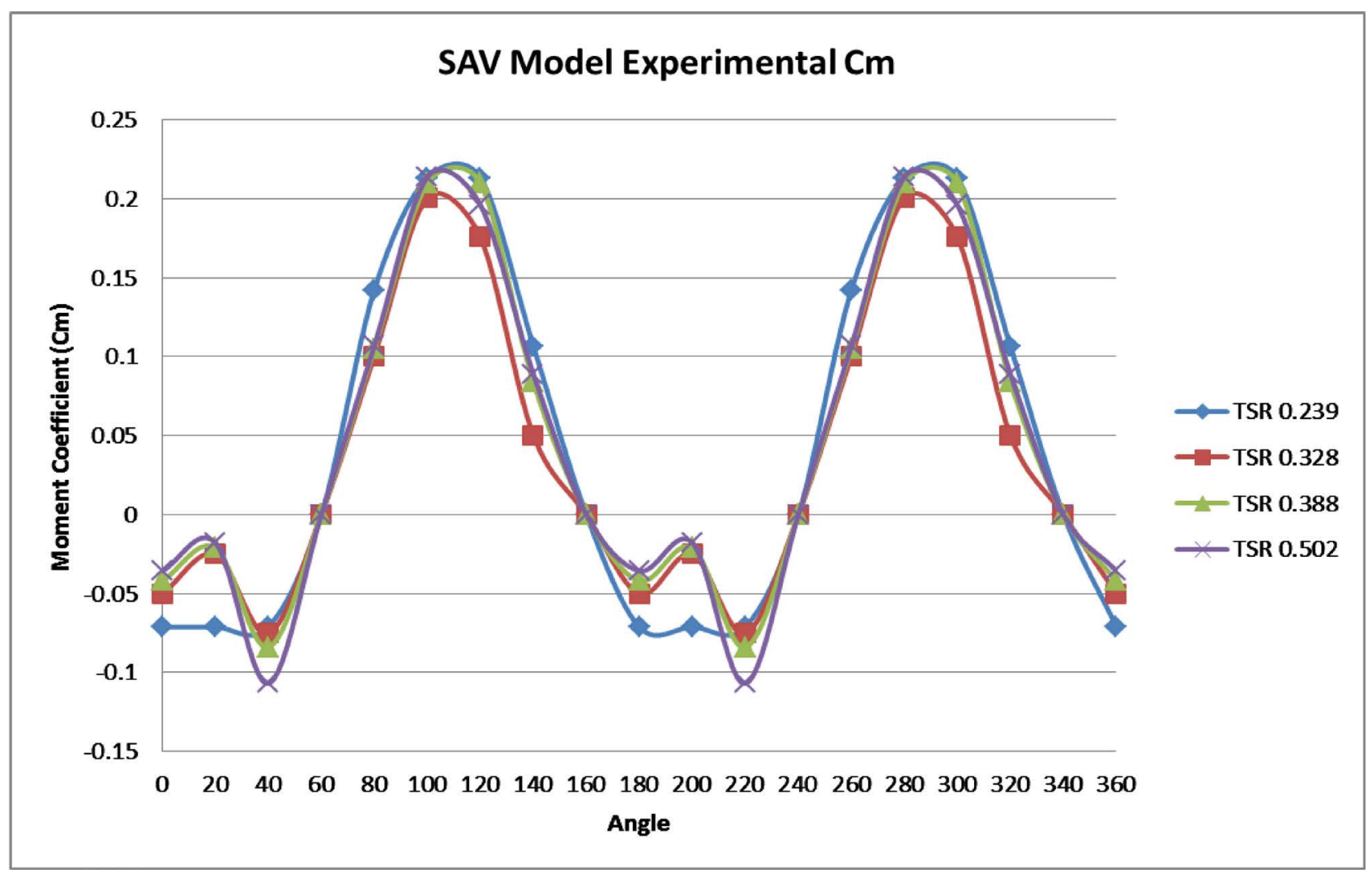

Figure 28. SAV model experimental moment coefficient. 


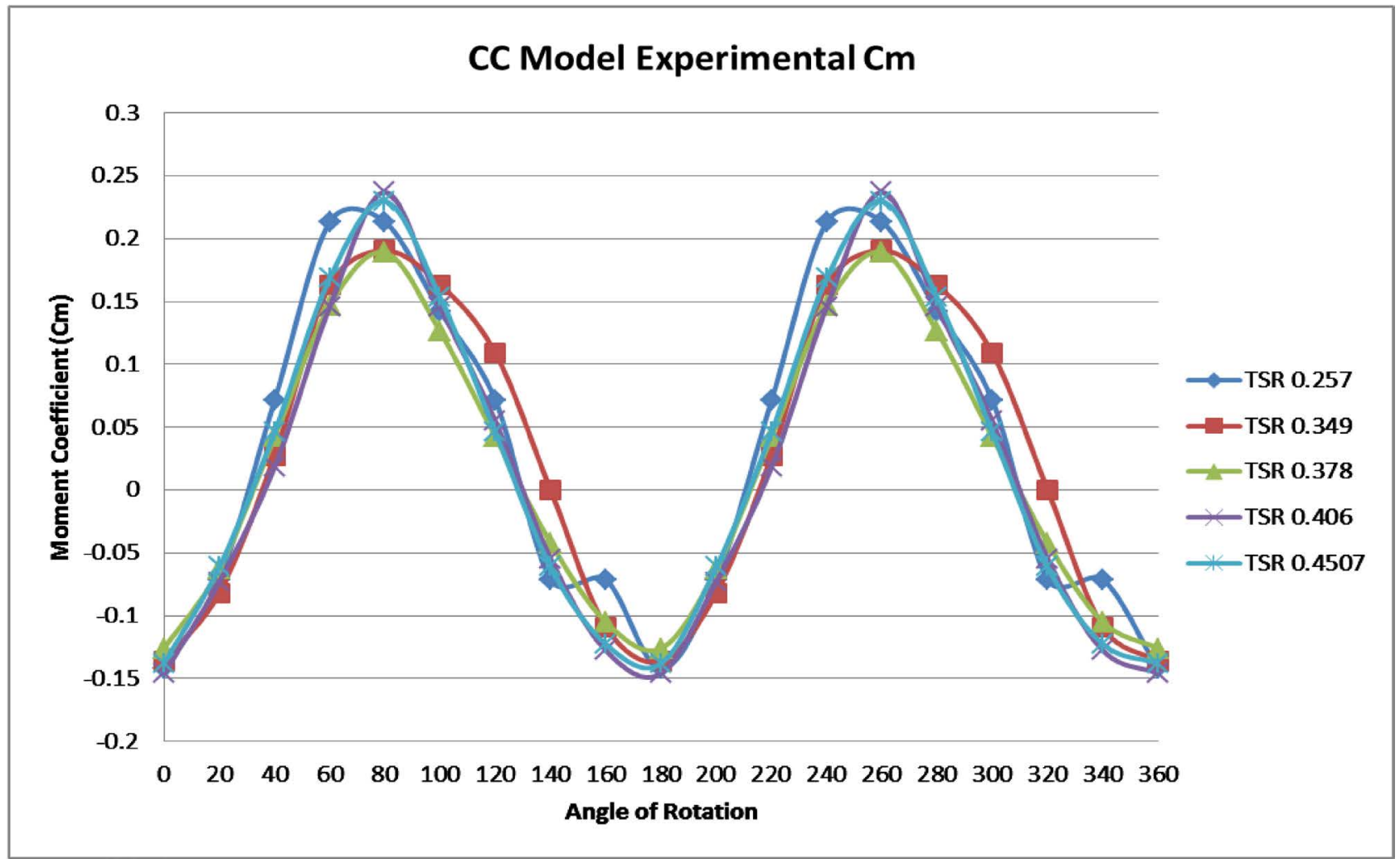

Figure 29. CC model experimental moment coefficient.

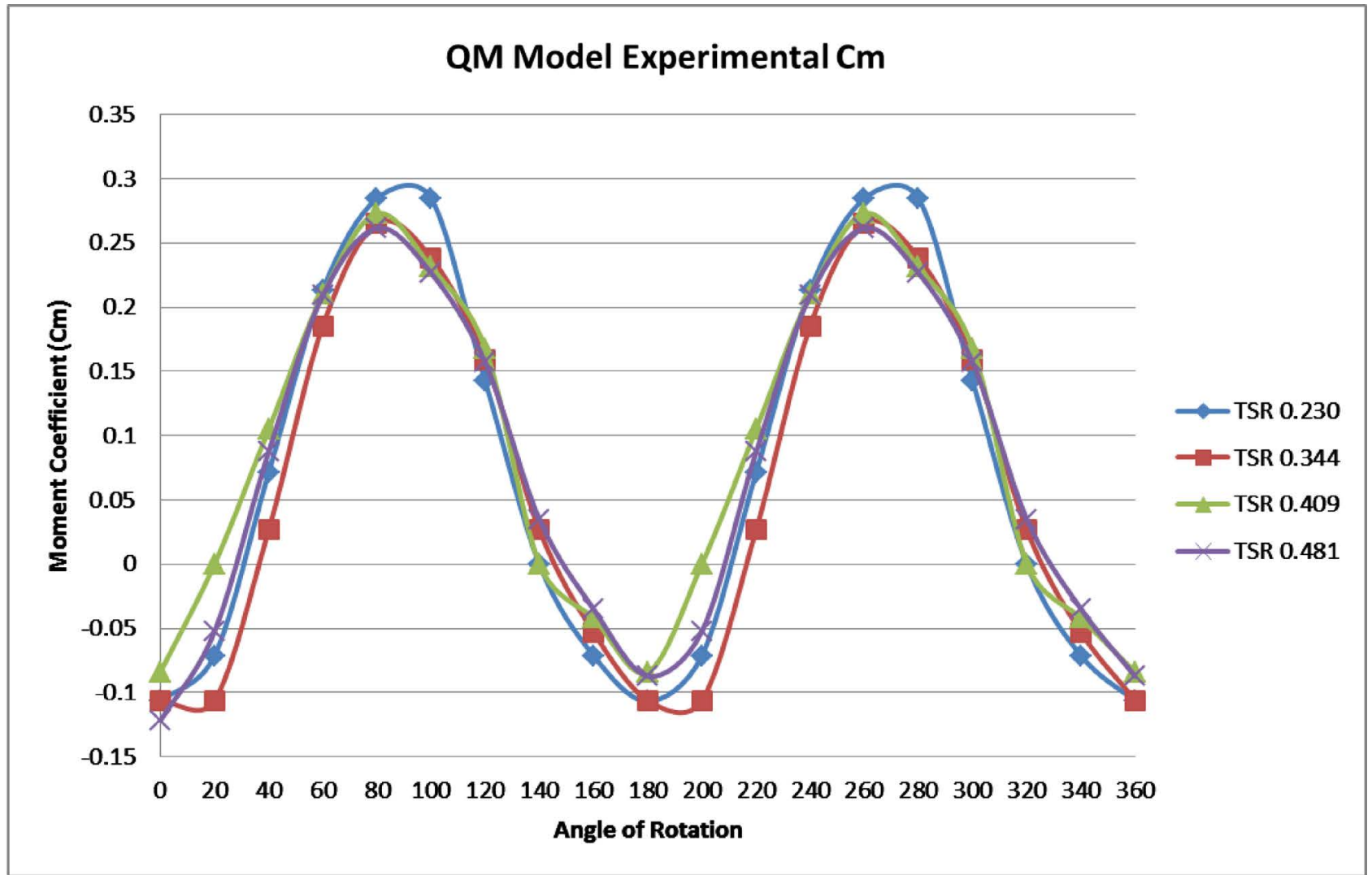

Figure 30. QM model experimental moment coefficient. 


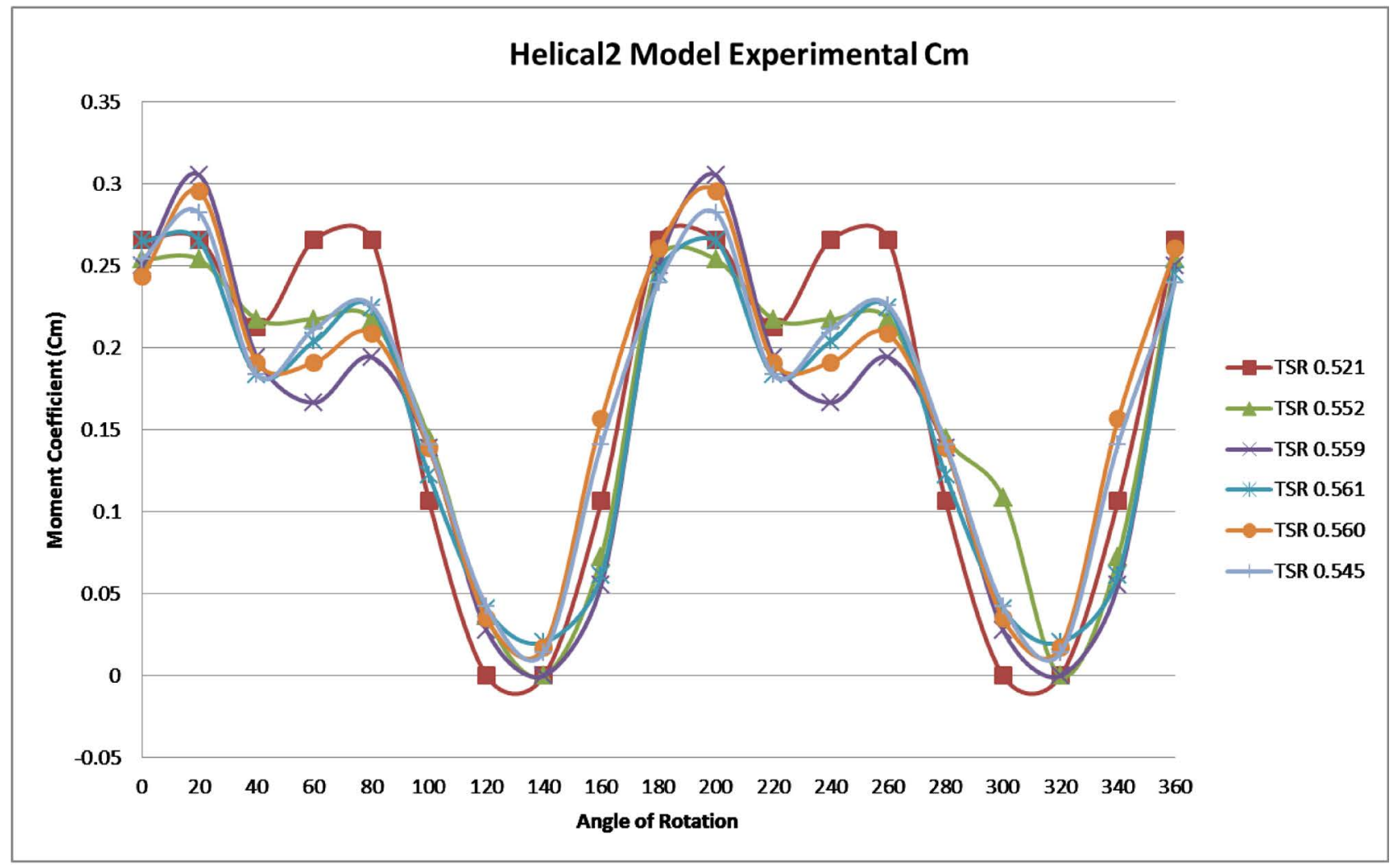

Figure 31. Helical 2 experimental moment coefficient.

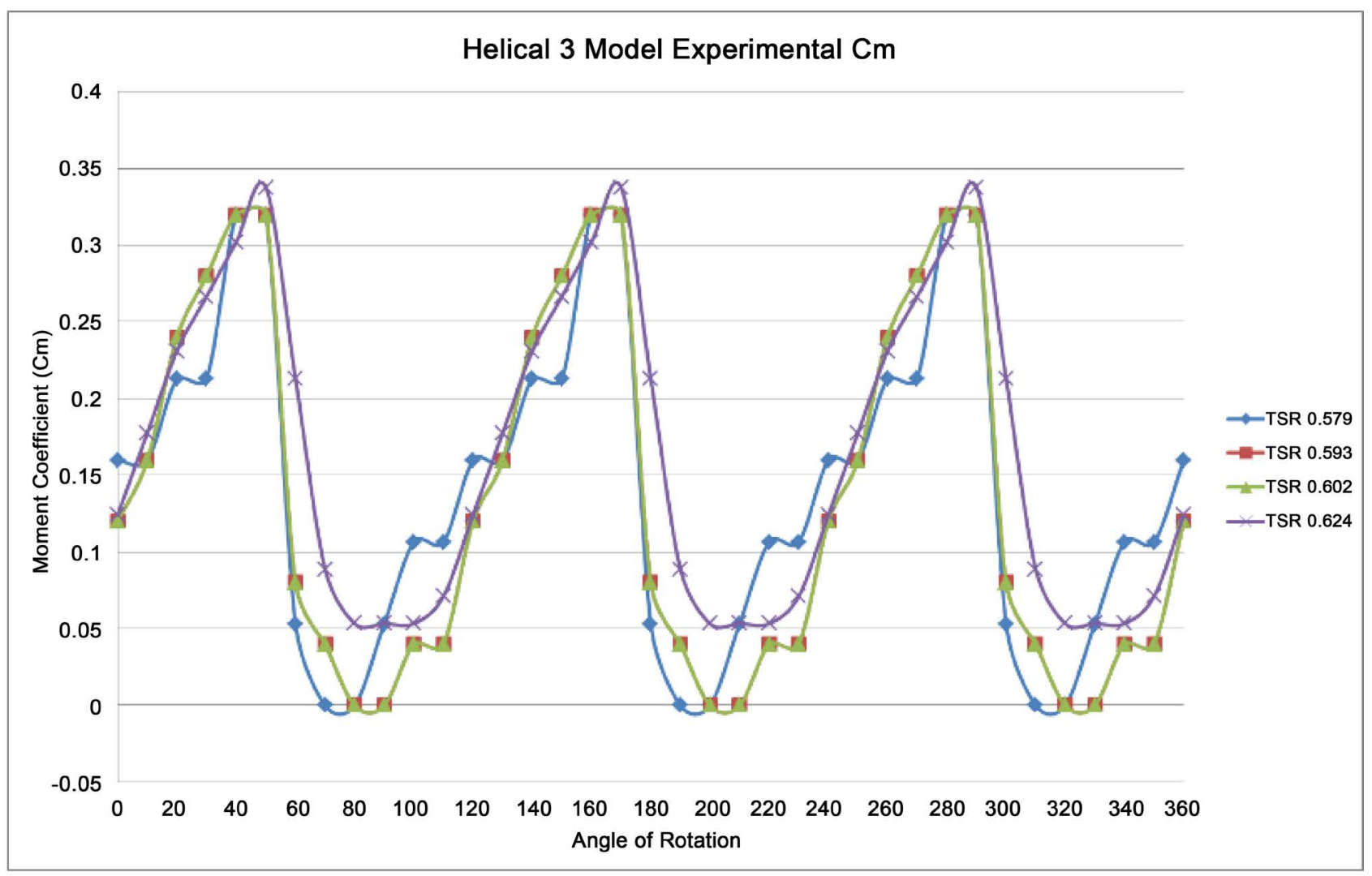

Figure 32. Helical 3 experimental moment coefficient. 


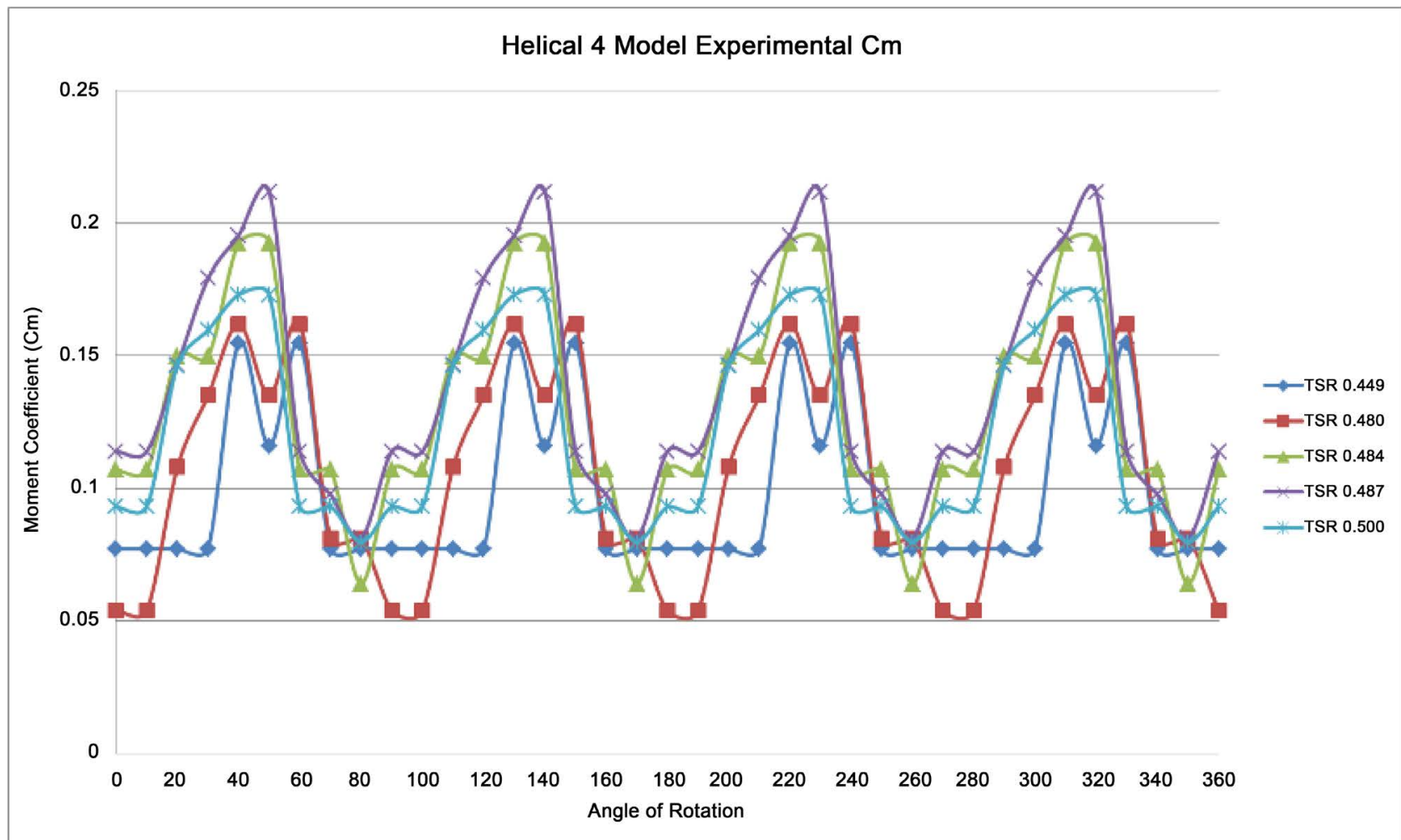

Figure 33. Helical 4 experimental moment coefficient.

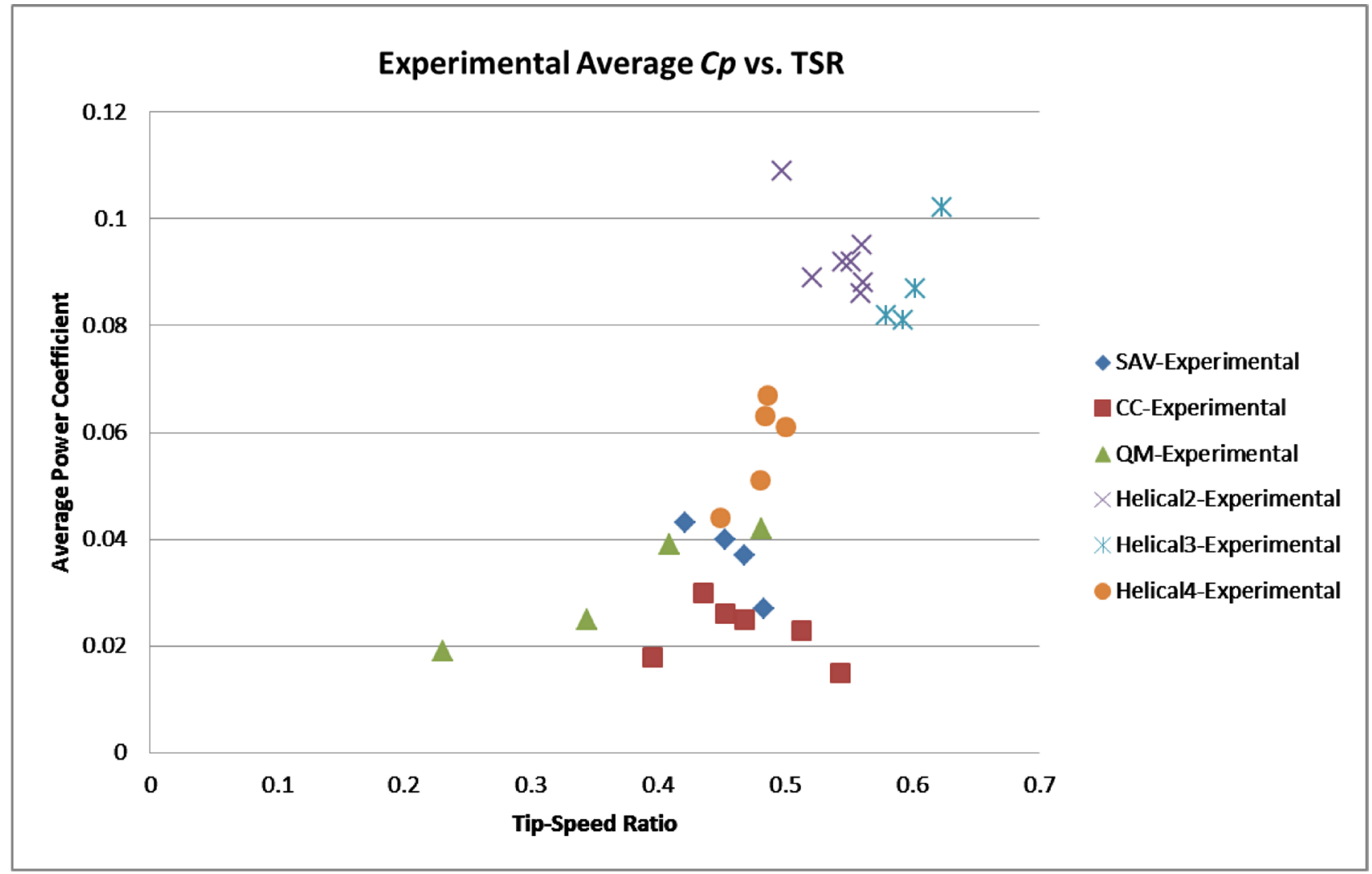

Figure 34. Experimental average power coefficient vs. tip-speed ratio for 6 model VAWTs. 


\subsection{Numerical Study of Helical Blades}

With experimental data for the helical models, numerical simulations with ANSYS Fluent are performed for validation of results. The same numerical methodology is used to obtain the following results; however, the wind velocity and corresponding RPM input boundary conditions are taken from the experimental data. This provides more realistic results for power coefficient vs. tip-speed ratio as the actual rotation of the VAWTs are modeled. Moment coefficient data from Fluent is used for calculating the average power coefficient for one full rotation. The results are plotted against corresponding tip-speed ratio in Figure 35.

Each data set is fitted with a fourth order polynomial trend line to display the power curves for the numerical results of the helical models.

\subsubsection{Pressure Contours Surrounding Blades}

This section contains the pressure contours surrounding the blades of the helical models. The cross-sections vary in the y-direction due to the blade twist, so three planes were created in post-processing for viewing results. The planes are located at the top, middle, and bottom of each model and are shown in Figure 36.

Pressure contours for the helical models at maximum power coefficient are presented in Table 6.

The Helical 2 model produces the highest power coefficient in the numerical study of 0.140 . Seen in Table 7, a greater pressure is developed on the inside of

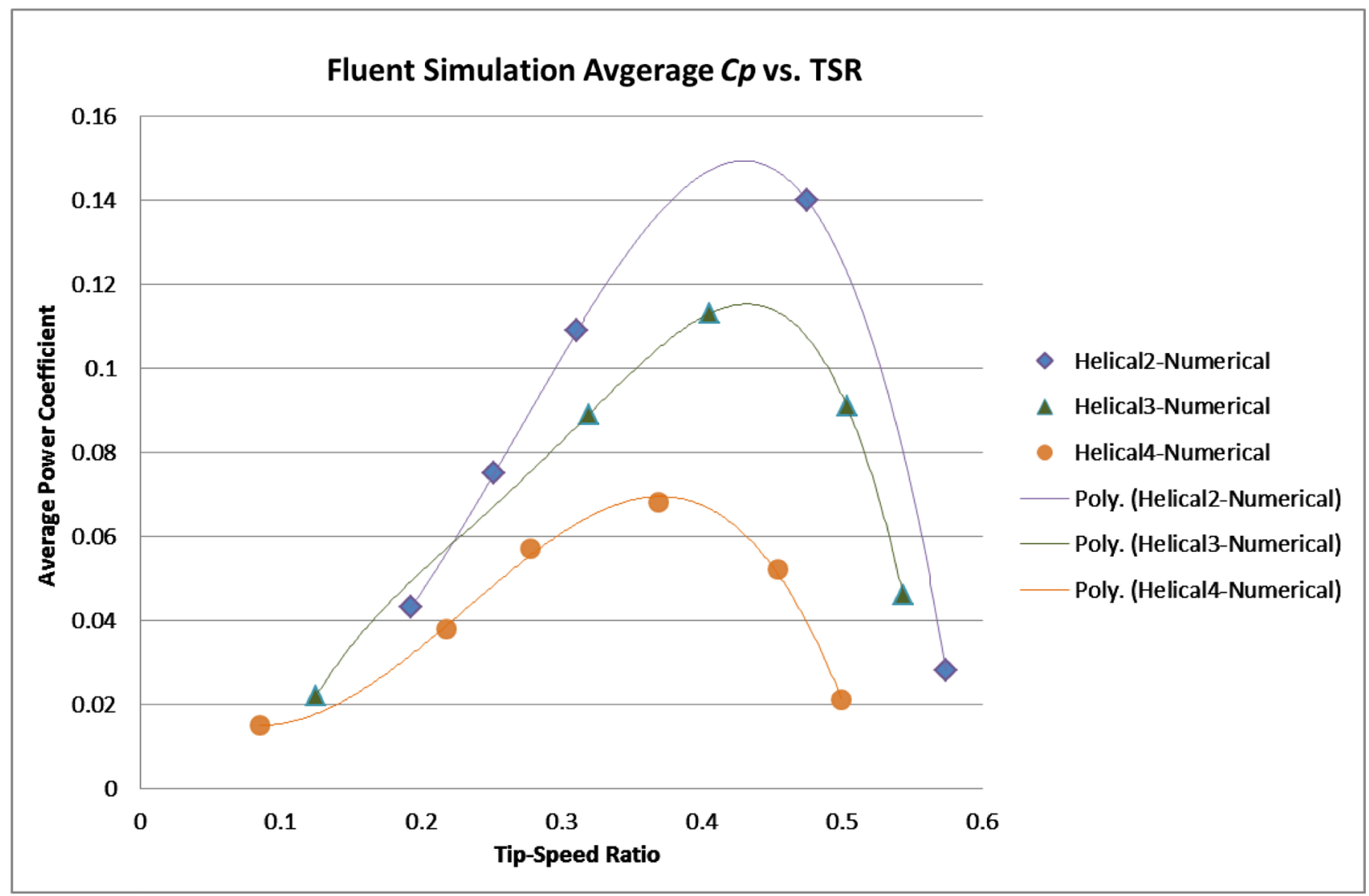

Figure 35. Fluent simulation power coefficient vs. tip-speed ratio for helical models. 


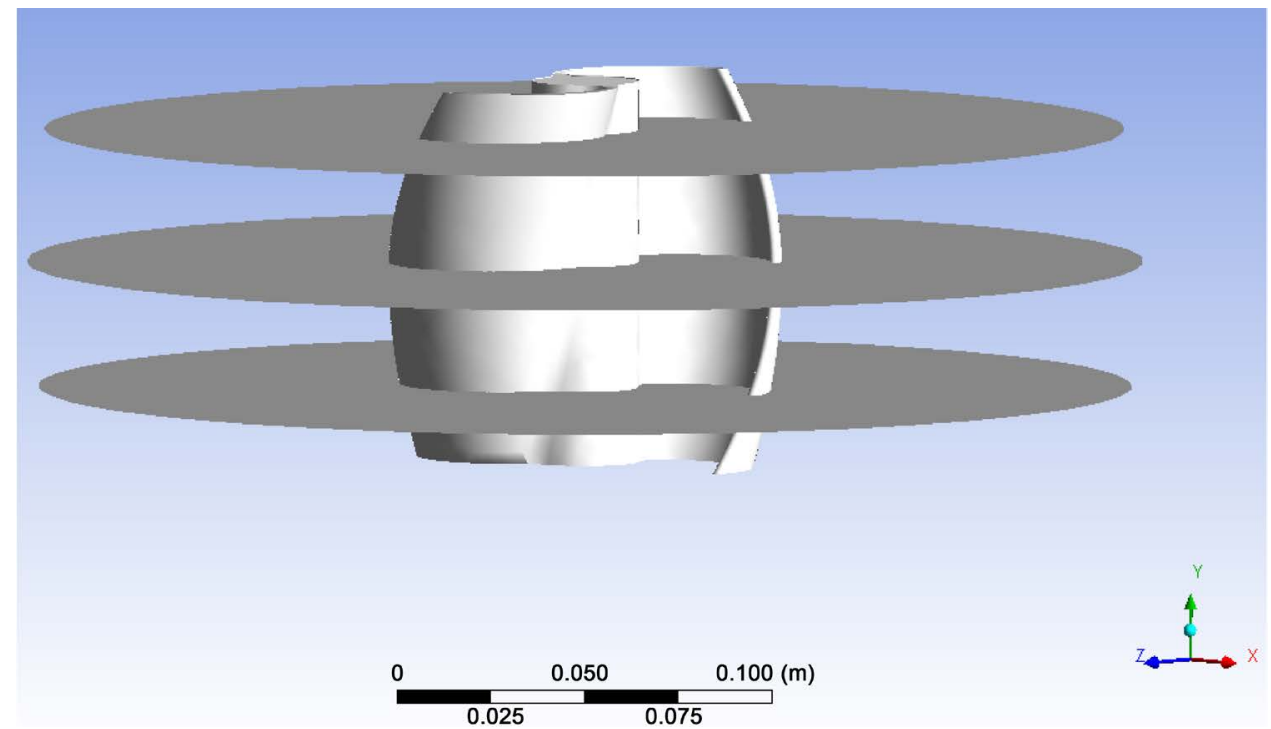

Figure 36. Planes a (top), b (middle), and c (bottom) for presenting helical model results.

Table 6. Pressure contours for helical models at maximum power coefficients.

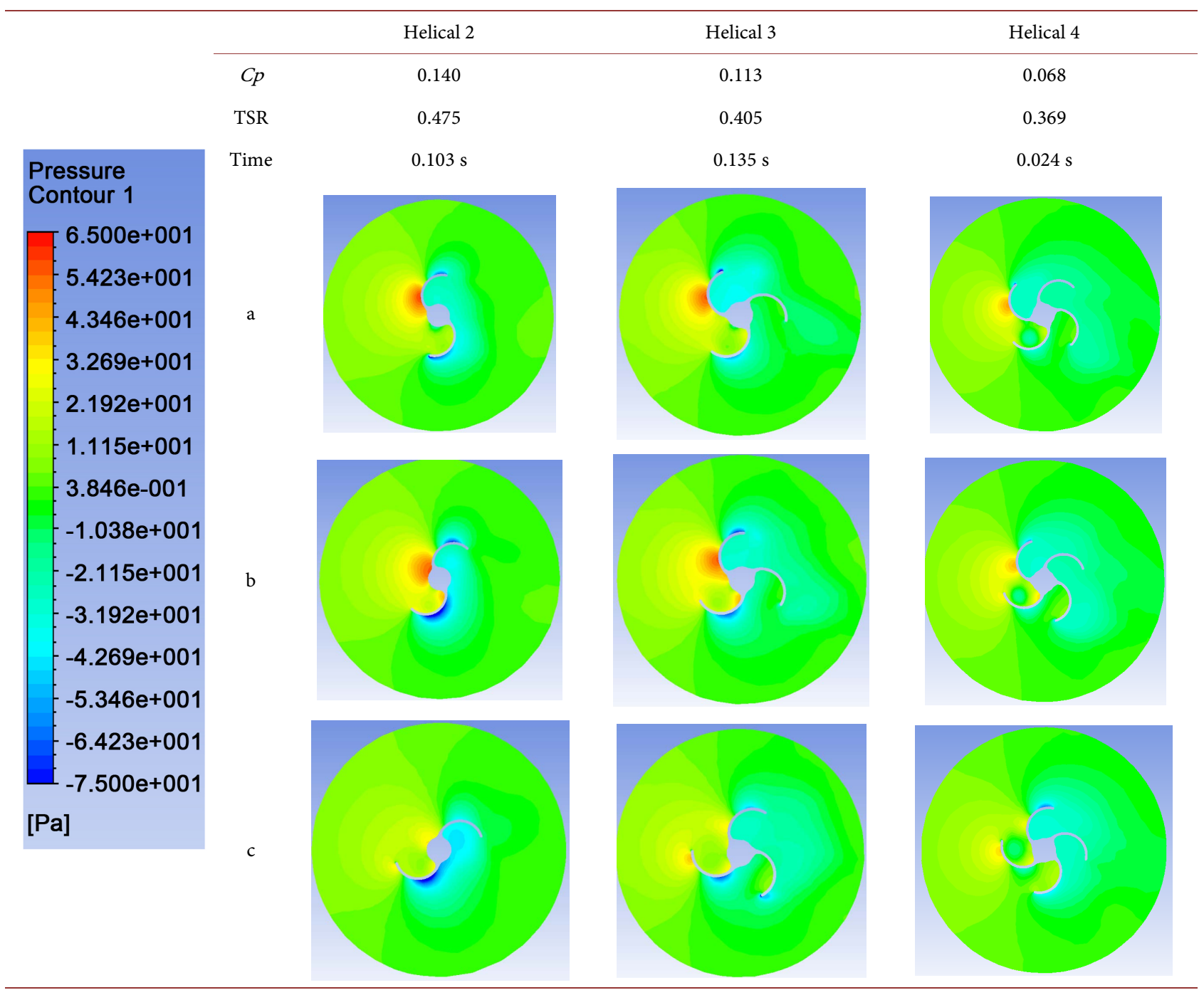


Table 7. Velocity contours for helical models at maximum power coefficients.

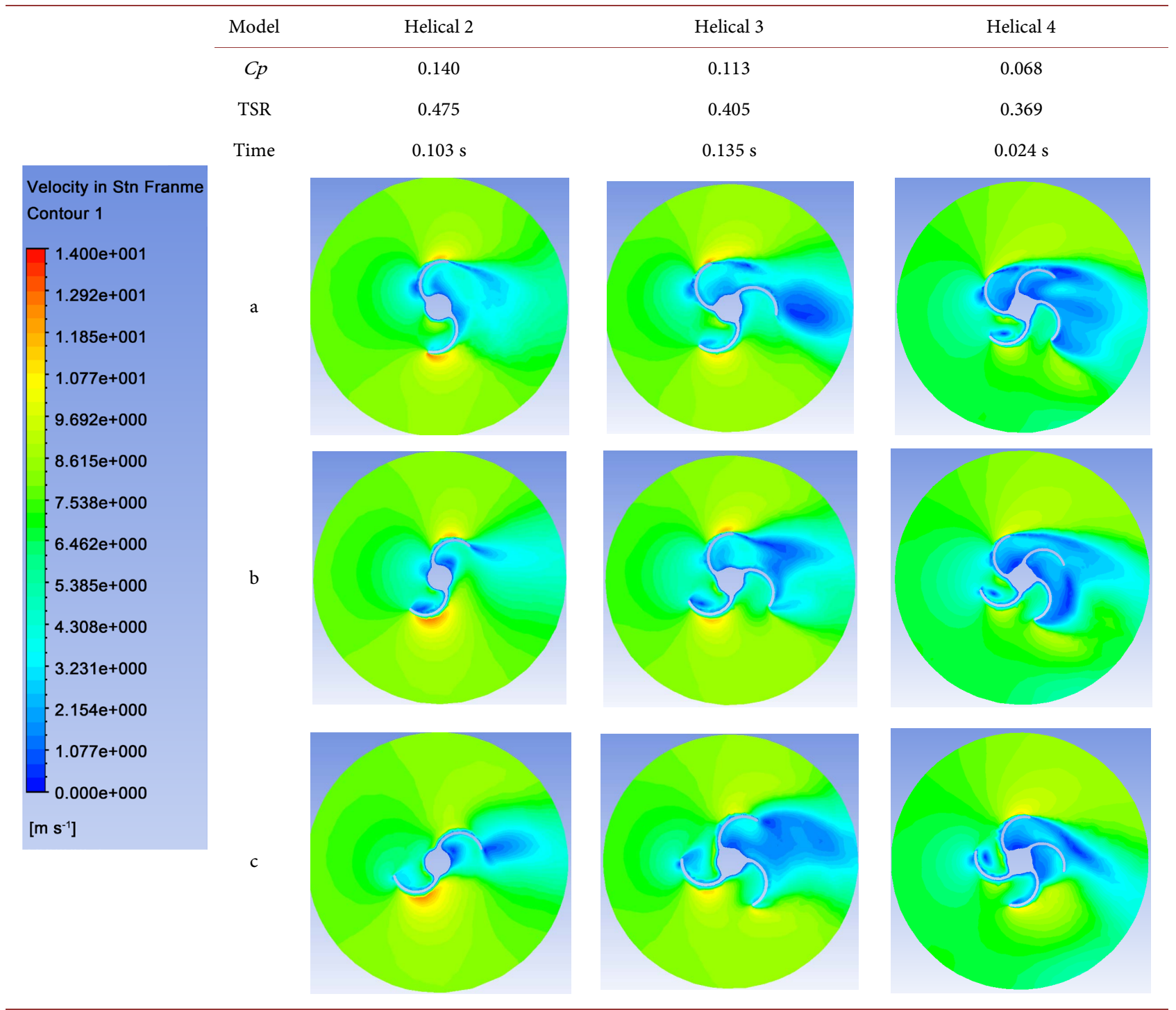

the retreating blade, and more negative pressure is present on the backside. This results in larger pressure differential on the blade, compared to the other 2 models, allowing for the higher turbine efficiency.

\subsubsection{Air Velocity Surrounding Blades}

Air velocity contours and vectors are displayed in Table 7 and Table 8, respectively.

In all 3 planes, higher air velocity is present on the backside of the bottom blade for the Helical 2 model. This creates the lower pressure seen in Table 6. The Helical 3 and Helical 4 models both produce significant wake behind the models, decreasing efficiency.

Vectors are shown along with contour plots to display air flow direction around the models. Air swirling is present behind the helical models with 2 and 3 blades, reinforcing the observations stated before. 
Table 8. Air velocity vectors for helical models at maximum power coefficients.

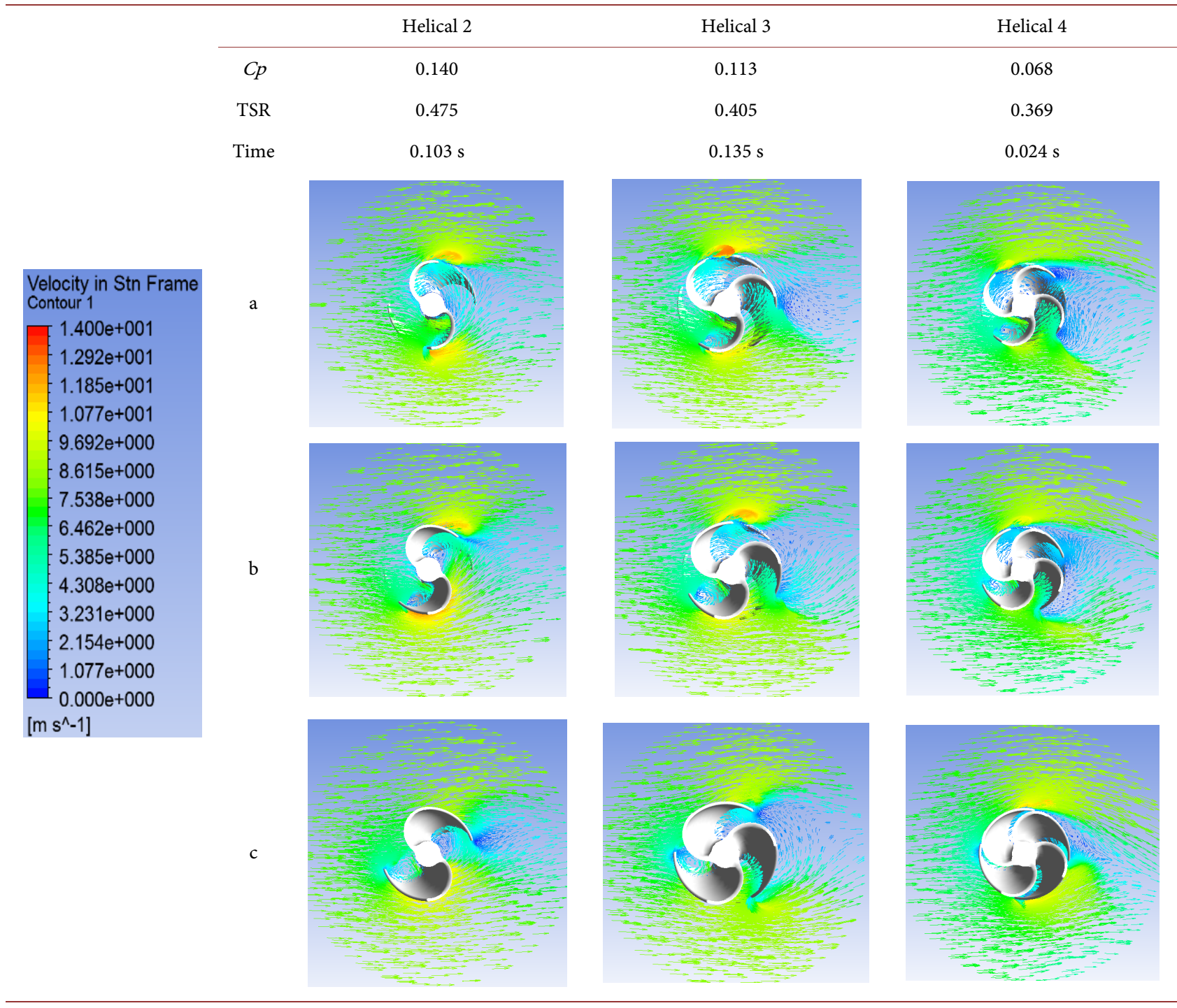

\subsection{Comparison of Experimental and Numerical Results for Helical Models}

The experimental and numerical power coefficient results are plotted together with corresponding tip-speed ratios for the helical models in Figures 37-39.

For both numerical study and wind tunnel experimentation, the Helical 2 model produces maximum power coefficient. Experimentally, maximum $C P$ of 0.109 is observed at TSR 0.497. Maximum $C p$ achieved for numerical simulation is 0.140 at TSR 0.475 .

Helical 3 achieves maximum experimental $C P$ of 0.102 at TSR 0.623 and maximum numerical $C p$ of 0.113 at TSR 0.405 .

Lowest efficiencies are observed with the Helical 4 model: experimental $C p$ of 0.067 at TSR 0.486 and numerical $C P$ of 0.068 at TSR 0.369 .

The Helical 2 numerical results are plotted alongside the reported efficiency for traditional Savonius rotors. The comparison can be seen in Figure 40. 


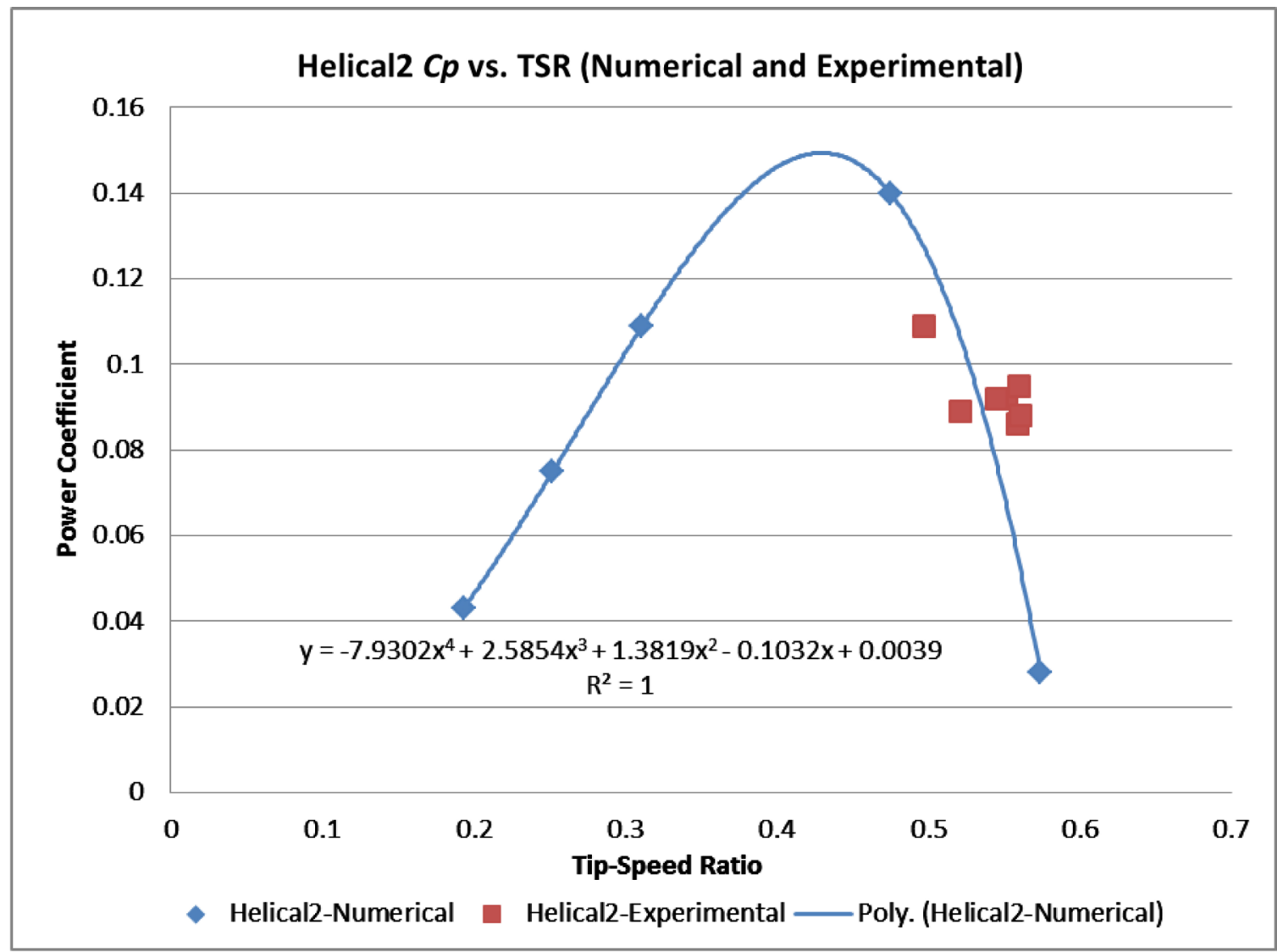

Figure 37. Numerical and experimental comparison for Helical 2.

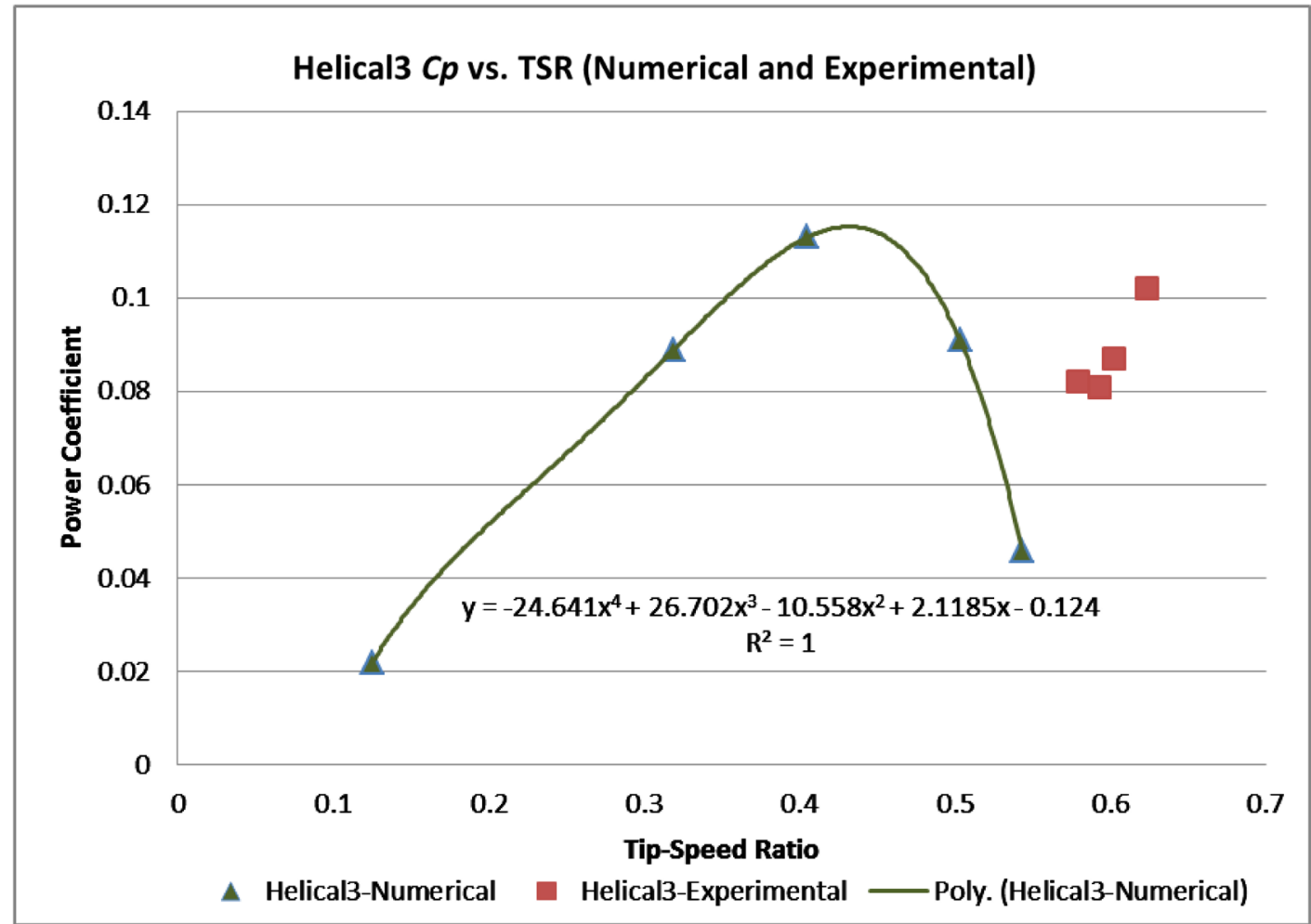

Figure 38. Numerical and experimental comparison for Helical 3. 


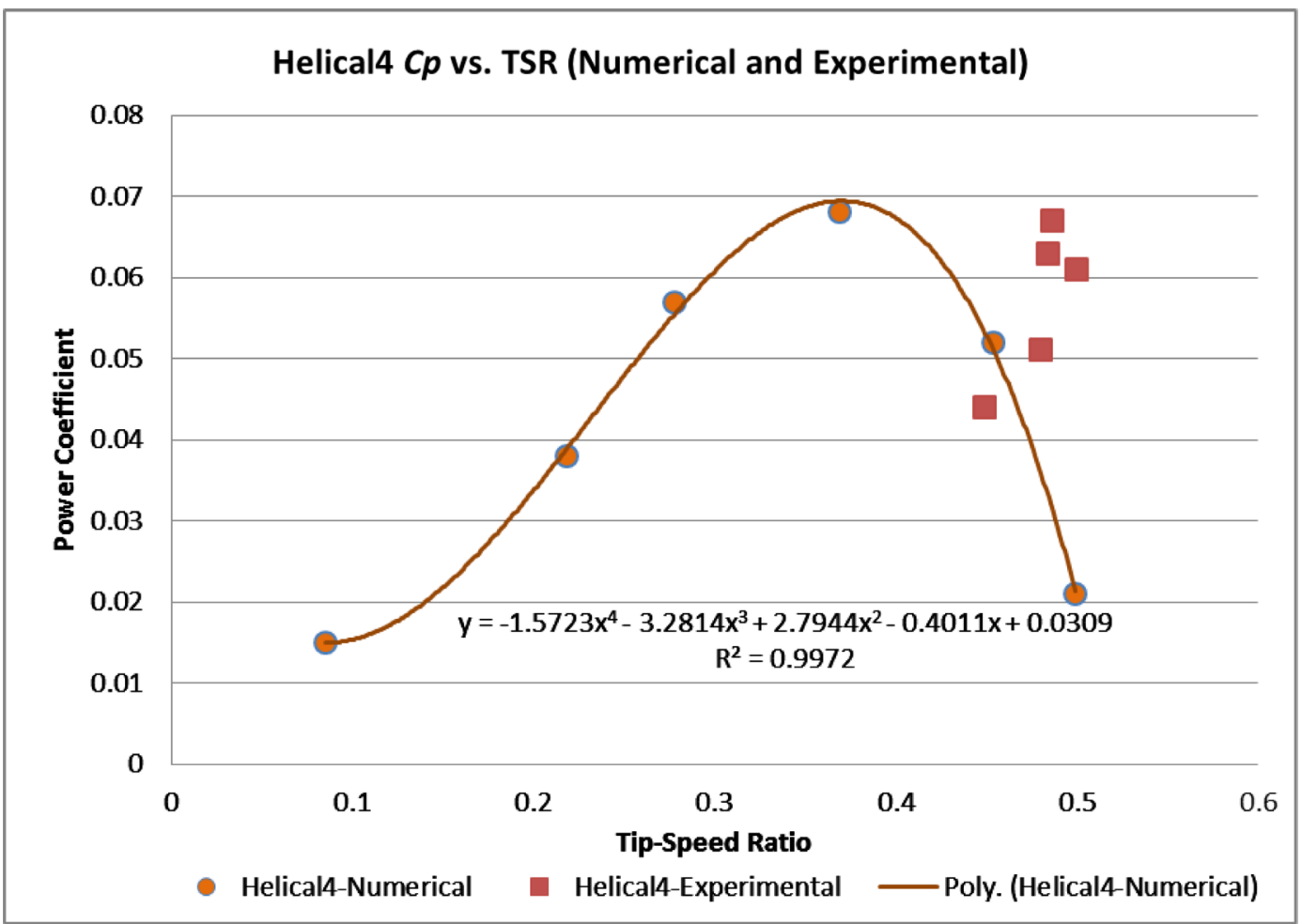

Figure 39. Numerical and experimental comparison for Helical 4.

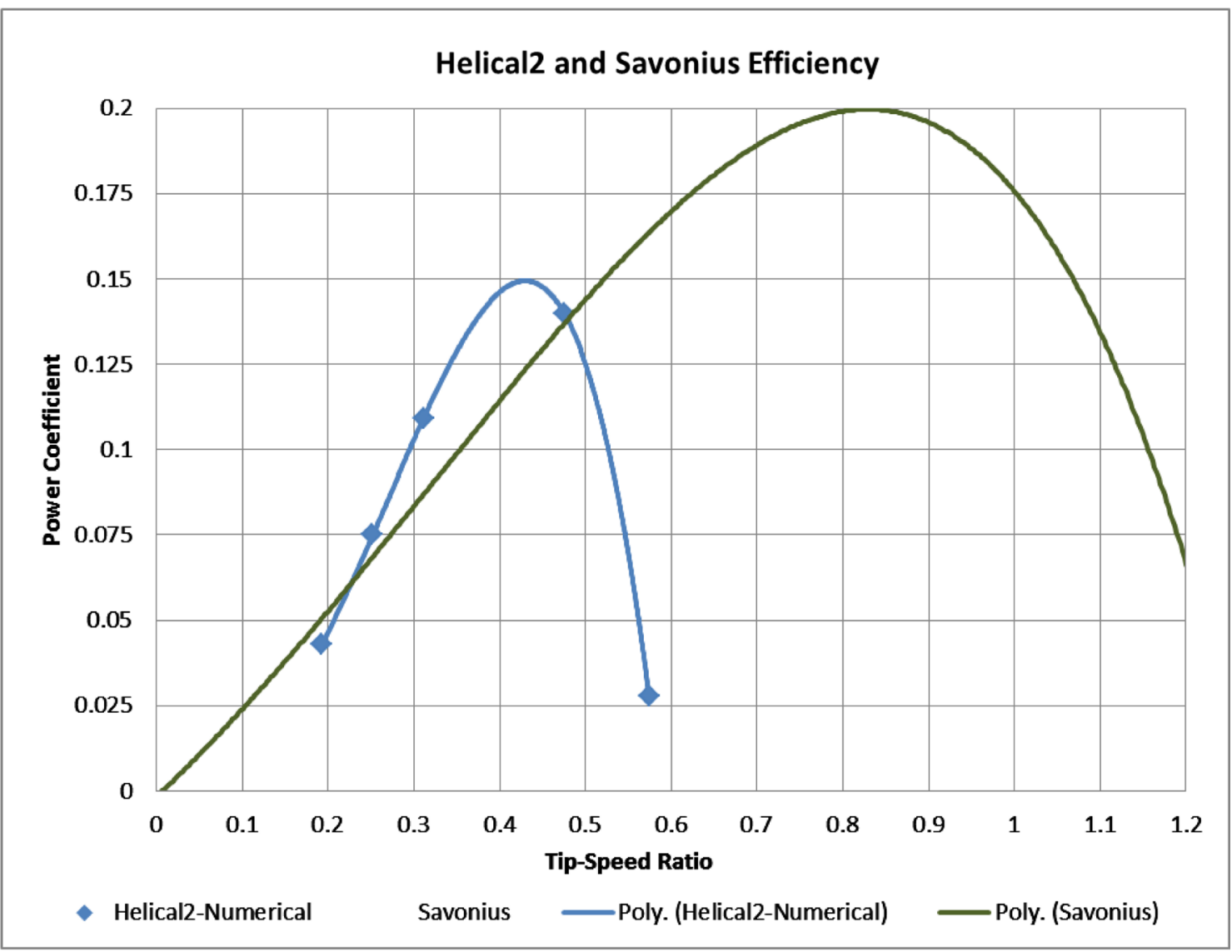

Figure 40. Helical 2 and Savonius Efficiency. 
In terms of wind turbine efficiency, a performance increase is observed for the Helical 2 model in the tip-speed ratio range of 0.25 to 0.475 . At TSR 0.375 , the helical turbine achieves just over a $3 \%$ increase in efficiency, compared to the traditional Savonius rotor.

To calculate the fluid characteristic parameters in our simulation; The ANSYS software has powerful design exploration and optimization capabilities by varying parameters from $\mathrm{CAD}$, material properties, boundary conditions and simulation results. It can quickly set up and evaluate multiple design variations to drive design of experiments, goal-driven optimization and Six Sigma analysis. ANSYS technology has the required capabilities to make model setup, meshing and physics solution enabling reliable and accurate fluid, structural, thermal, electromagnetic and multiphysics simulations [31].

\section{Conclusions}

The following conclusions are drawn from the study:

- The new QM and CC cross-section design for Savonius rotors create a center of pressure further from the axis of rotation, increasing power coefficient.

- Both the QM and CC designs reduce the total range of negative torque on the blades by 20 degrees, compared to the traditional SAV model.

- 90 degree helical twist models with 2 - 4 blades each experience positive torque for all angles of operation, while Savonius models experience negative torque in 2 regions.

- Helical 2 and Helical 3 possess the best self-starting capability. Helical 3: 35 RPM at $1.4 \mathrm{~m} / \mathrm{s}$ wind speed and Helical 2: $45 \mathrm{RPM}$ at $1.5 \mathrm{~m} / \mathrm{s}$ wind speed.

- Highest average power coefficient observed in the study (1 complete rotation) is achieved by the Helical 2 model, both numerically and experimentally. Simulation: $C P=0.140$ at tip-speed ratio $=0.475$, and Wind tunnel experiment: $C p=0.109$ at tip-speed ratio $=0.497$.

- At TSR 0.375, the Helical 2 turbine achieves just over a 3\% increase in efficiency, compared to the reported efficiency of a traditional Savonius rotor. Increased power coefficient is observed for Helical 2 in the tip-speed ratio range of 0.25 to 0.475 .

\section{Acknowledgements}

Authors would express the heartiest deep sense of gratitude to Mechanical Engineering Department of Georgia Southern University for financial support, reference papers, and websites as mentioned below which are necessary for the research. Also, authors acknowledge NSF-RET: ENgaging Educators in Renewable EnerGY (ENERGY), Total Award Amount: \$524,706, Award \#1609524, Total Award Period Covered: June 1, 2016-May 31, 2019.

\section{References}

[1] Wind Vision (2016) A New Era for Wind Power in the United States. 
ENERGY.GOV. http://www.offshorewindhub.org/resource/1540

[2] Khan, J., Bashar, M.M. and Rahman, M. (2013) Computational Studies on the Flow Field of Various Shapes-Bladed Vertical Axis Savonius Turbine in Static Condition. ASME 2013 International Mechanical Engineering Congress and Exposition, San Diego, CA, 15-21 November 2013, V06BT07A086.

[3] Morshed, K.N., Rahman, M., Molina, G. and Ahmed, M. (2013) Wind Tunnel Testing and Numerical Simulation on Aerodynamic Performance of a Three Bladed Savonius Wind Turbine. International Journal of Energy and Environmental Engineering, 4, 18.

[4] Ghatage, S.V. and Joshi, J.B. (2012) Optimisation of Vertical Axis Wind Turbine: CFD Simulations and Experimental Measurements. Canadian Journal of Chemical Engineering, 90, 1186-1201.

[5] Abraham, J.P., Mowry, G.S., Plourde, B.P., Sparrow, E.M. and Minkowycz, W.J. (2011) Numerical Simulation of Fluid Flow around a Vertical-Axis Turbine. Journal of Renewable \& Sustainable Energy, 3, 033109. https://doi.org/10.1063/1.3588037

[6] Kang, C., Yang, X. and Wang, Y.L. (2013) Turbulent Flow Characteristics and Dynamics Response of a Vertical-Axis Spiral Rotor. Energies, 6, 2741-2758.

[7] Díaz, P., Argemiro, G.J.P. and Salas, K.U. (2015) Computational Model of Savonius Turbine. INGENIARE - Revista Chilena De Ingeniería, 23, 406-412.

[8] Bachu, D., Rajat, G. and Misra, R.D. (2013) Performance Analysis of a Helical Savonius Rotor without Shaft at $45^{\circ}$ Twist Angle Using CFD. Journal of Urban \& Environmental Engineering, 7, 126-133.

[9] Kamoji, M.A., Kedare, S.B. and Prabhu, S.V. (2009) Performance Tests on Helical Savonius Rotors. Renewable Energy, 34, 521-529.

[10] Ricci, R., Romagnoli, R., Montelpare, S. and Vitali, D. (2016) Experimental Study on a Savonius Wind Rotor for Street Lighting Systems. Applied Energy, 161, 143-152. https://doi.org/10.1016/j.apenergy.2015.10.012

[11] Jeon, Keum Soo, Jun Ik Jeong, Jae-Kyung Pan, and Ki-Wahn Ryu, (2014) Effects of End Plates with Various Shapes and Sizes on Helical Savonius Wind Turbines. Renewable Energy, 79, 167-176. https://doi.org/10.1016/j.renene.2014.11.035

[12] Deb, B., Gupta, R. and Misra, R.D. (2014) Experimental Analysis of a $20^{\circ}$ Twist Helical Savonius Rotor at Different Overlap Conditions. Applied Mechanics \& Materialsno, 592-594, 1060-1064.

[13] Wenehenubun, F., Saputra, A. and Sutanto, H. (2015) An Experimental Study on the Performance of Savonius Wind Turbines Related with the Number of Blades. Energy Procedia, 68, 297-304. https://doi.org/10.1016/j.egypro.2015.03.259

[14] Saha, U., Thotla, S. and Maity, D. (2008) Optimum Design Configuration of Savonius Rotor through Wind Tunnel Experiments. Journal of Wind Engineering \& Industrial Aerodynamics, 96, 1359-1375. https://doi.org/10.1016/j.jweia.2008.03.005

[15] Mohamed, M.H. (2012) Performance Investigation of H-Rotor Darrieus Turbine with New Airfoil Shapes. Energy, 47, 522-530.

[16] Armstrong, S., Fiedler, A. and Tullis, S. (2012) Flow Separation on a High Reynolds Number, High Solidity Vertical Axis Wind Turbine with Straight and Canted Blades and Canted Blades with Fences. Renewable Energy. An International Journal, 41, 13-22.

[17] Beri, H. and Yao, Y.X. (2011) Numerical Simulation of Unsteady Flow to Show Self-Starting of Vertical Axis Wind Turbine Using Fluent. Journal of Applied Sciences, 11, 962-970. 
[18] Gorelov, D. and Krivospitsky, V. (2008) Prospects for Development of Wind Turbines with Orthogonal Rotor. Thermophysics \& Aeromechanics, 15, 153.

[19] Kou, W., Shi, X.C., Yuan, B. and Fan, L.T. (2011) Modeling Analysis and Experimental Research on a Combined-Type Vertical Axis Wind Turbine. International Conference on Electronics, Communications \& Control (ICECC), Ningbo, 9-11 September 2011. https://doi.org/10.1109/ICECC.2011.6067999

[20] Gupta, R., Biswas, A. and Sharma, K.K. (2008) Comparative Study of a Three-Bucket Savonius Rotor with a Combined Three-Bucket Savonius-Three-Bladed Darrieus Rotor. Renewable Energy: An International Journal, 33, 1974-1981.

[21] Bhuyan, S. and Biswas, A. (2014) Investigations on Self-Starting and Performance Characteristics of Simple $\mathrm{H}$ and Hybrid H-Savonius Vertical Axis Wind Rotors. Energy Conversion \& Management, 87, 859-867. https://doi.org/10.1016/j.enconman.2014.07.056

[22] Islam, M., Ting, D.S.-K. and Fartaj, A. (2008) Aerodynamic Models for Darrieus-Type Straight-Bladed Vertical Axis Wind Turbines. Renewable \& Sustainable Energy Reviews, 12, 1087-1109.

[23] Pope, K., Naterer, G.F., Dincer, I. and Tsang, E. (2011) Power Correlation for Vertical Axis wind Turbines with Varying Geometries. International Journal of Energy Research, 35, 423-435.

[24] Alaimo, A., Esposito, A., Messineo, A., Orlando, C. and Tumino, D. (2015) 3D CFD Analysis of a Vertical Axis Wind Turbine. Energies, 8, 3013-3033.

[25] ANSYS (2012) Fluent Theory Guide-ANSYS Release Version 15.0, User's Guide. ANSYS Inc., Canonsburg, PA.

[26] Sagol, E., Reggio, M. and Ilinca, A. (2012) Assessment of Two-Equation Turbulence Models and Validation of the Performance Characteristics of an Experimental Wind Turbine by CFD. ISRN Mechanical Engineering, 2012, Article ID: 428671. https://doi.org/10.5402/2012/428671

[27] http://centurionenergy.net/types-of-wind-turbines

[28] http://www.green-mechanic.com/2013/04/advantages-and-disadvantages-of.html

[29] http://kohilowind.com/kohilo-university/202-types-of-wind-turbines-their-advanta ges-disadvantages/

[30] FLUENT Manual (2012) ANSYS Release Version 15.0, User's Guide; ANSYS Inc., Canonsburg, PA.

[31] http://www.ansys.com/products/3d-design/ansys-aim/aim-capabilities 